\title{
microRNA as Repressors of Stress-Induced Anxiety: The Case of Amygdalar miR-34
}

\author{
Sharon Haramati, ${ }^{1}$ Inbal Navon, ${ }^{1}$ Orna Issler, ${ }^{1}$ Gili Ezra-Nevo, ${ }^{1}$ Shosh Gil, ${ }^{1}$ Raaya Zwang, ${ }^{1}$ Eran Hornstein, ${ }^{2}$ \\ and Alon Chen ${ }^{1}$ \\ Departments of ${ }^{1}$ Neurobiology and ${ }^{2}$ Molecular Genetics, Weizmann Institute of Science, Rehovot 76100, Israel
}

The etiology and pathophysiology of anxiety and mood disorders is linked to inappropriate regulation of the central stress response. To determine whether microRNAs have a functional role in the regulation of the stress response, we inactivated microRNA processing by a lentiviral-induced local ablation of the Dicer gene in the central amygdala (CeA) of adult mice. CeA Dicer ablation induced a robust increase in anxiety-like behavior, whereas manipulated neurons survive and appear to exhibit normal gross morphology in the time period examined. We also observed that acute stress in wild-type mice induced a differential expression profile of microRNAs in the amygdala. Bioinformatic analysis identified putative gene targets for these stress-responsive microRNAs, some of which are known to be associated with stress. One of the prominent stress-induced microRNAs found in this screen, miR-34c, was further confirmed to be upregulated after acute and chronic stressful challenge and downregulated in Dicer ablated cells. Lentivirally mediated overexpression of miR34c specifically within the adult CeA induced anxiolytic behavior after challenge. Of particular interest, one of the miR-34c targets is the stress-related corticotropin releasing factor receptor type 1 (CRFR1) mRNA, regulated via a single evolutionary conserved seed complementary site on its $3^{\prime}$ UTR. Additional in vitro studies demonstrated that miR-34c reduces the responsiveness of cells to CRF in neuronal cells endogenously expressing CRFR1. Our results suggest a physiological role for microRNAs in regulating the central stress response and position them as potential targets for treatment of stress-related disorders.

\section{Introduction}

In response to stress, the brain activates various neuronal systems designed to adapt to the demand (Joëls and Baram, 2009). Inappropriate regulation, disproportional intensity, or chronic and/or irreversible activation of the stress response is linked to the etiology and pathophysiology of anxiety and mood disorders (de Kloet et al., 2005; McEwen, 2007). MicroRNAs (miRNAs) are a subset of endogenous small RNA molecules that regulate gene expression posttranscriptionally. Much is known regarding miRNA biogenesis and function (Bartel, 2009; Carthew and Sontheimer, 2009; Chekulaeva and Filipowicz, 2009; Kim et al., 2009; Fabian et al., 2010). Briefly, miRNA primary transcripts are cleaved into a $\sim 70$ nt pre-miRNA that is further processed by Dicer into an RNA duplex of $\sim 20 \mathrm{bp}$. A mature single-strand

\footnotetext{
Received April 4, 2011; revised July 17, 2011; accepted Aug. 5, 2011.

Author contributions: S.H., E.H., and A.C. designed research; S.H., I.N., 0.I., G.E.-N., S.G., and R.Z. performed research; E.H. contributed unpublished reagents/analytic tools; S.H., I.N., and 0.I. analyzed data; S.H. and A.C. wrote the paper.

A.C. is an incumbent of the Philip Harris and Gerald Ronson Career Development Chair. This work is supported by FP7 Grant 260463 from the European Research Council, a research grant from the Israel Science Foundation, a research grant from Roberto and Renata Ruhman, a research grant from the Legacy Heritage Biomedical Science Partnership, a research grant from the Israel Ministry of Health, a grant from Mike Kahn, a research grant from Jorge David Ashkenazi, a research grant from Barry Wolfe, and a research grant from Nella and Leon Benoziyo Center for Neurosciences. We thank Dr. Ester Feldmesser, Dr. Shirley Horn-Saban, and Mati Mann for help in the establishment of the miRNA array procedure and analysis, Dr. Shifra Ben-Dor for bioinformatics consulting, Ayelet Cooper for the E/syn-pCSC construct, and Dr. Raya Eilam for assisting in the IHC procedures.

Correspondence should be addressed to Dr. Alon Chen, Department of Neurobiology, Weizmann Institute of Science, Rehovot 76100, Israel. E-mail: alon.chen@weizmann.ac.il.

DOI:10.1523/JNEUROSCI.1673-11.2011

Copyright $\odot 2011$ the authors $\quad 0270-6474 / 11 / 3114191-13 \$ 15.00 / 0$
}

miRNA is then incorporated, in a Dicer-dependent process (Krol et al., 2010a), into the miRNA-induced silencing complex in which it induces translational repression or mRNA destabilization by base-pair targeting of mRNAs. miRNAs were shown to respond to various cellular stressors (Leung and Sharp, 2010) and are abundant in the nervous system, but research has mainly focused on neurons in the context of development and neurodegenerative disorders (Kim et al., 2007; Schaefer et al., 2007; Cuellar et al., 2008; Davis et al., 2008; De Pietri Tonelli et al., 2008; Dugas et al., 2010; Li and Jin, 2010; Zhao et al., 2010). It has been suggested that miRNAs play a role in psychiatric disorders such as schizophrenia and autism (Tabarés-Seisdedos and Rubenstein, 2009; Beveridge et al., 2010; Kim et al., 2010; Fénelon et al., 2011) and drug addiction (Im et al., 2010; Schaefer et al., 2010). Interestingly, miRNAs were recently implicated in the mechanism of action of antidepressants (Baudry et al., 2010). Several studies have suggested that miRNAs are involved in normal adult brain mechanisms, such as neural plasticity and memory (Ashraf and Kunes, 2006; Edbauer et al., 2010; Wibrand et al., 2010), sleeprelated processes (Davis et al., 2007), and circadian-clock modulation (Cheng et al., 2007). The amygdaloid complex is well established as a major element in fear integration and response generation, to both learned and unlearned threats (Rogan and LeDoux, 1996; Roozendaal et al., 2009). The central amygdala (CeA) involvement in the stress response is well documented and was studied in the context of different neuromodulators, such as corticotropin releasing factor (CRF) (Koob and Heinrichs, 1999; Keen-Rhinehart et al., 2009; Jankord and Herman, 2008), Oxytocin (Bosch et al., 2005; Ebner et al., 2005), and others. 
In this study, we aimed to elucidate the role of miRNAs in the adult amygdala, in the context of stress-related behavior. Toward this end, we studied the effect of miRNA depletion specifically in the CeA, on anxiety-like behavior in adult mice. We explored the physiological role of miRNAs in the regulation of the stress response, by examining amygdalar miRNA expression profile after acute restraint stress. We further demonstrated anxiolytic properties for miR-34c overexpression in the central amygdala and uncovered a role for miR-34c as a regulator of CRF signaling.

\section{Materials and Methods}

Animals

Dicer ${ }^{\text {flox }} /$ Dicer ${ }^{\text {flox }}$ mice (Harfe et al., 2005) were bred with Rosa26-Reporter-yellow fluorescent protein mice (R26R-YFP) (Srinivas et al., 2001) for several generations until all offspring carried both alleles homozygously. These double homozygous progeny were used for the CeA self-deleting Cre recombinase (sdCre) injections (CeA-Dicer-KO) experiments and the neuronal primary culture experiments. Adult male C57BL/6 (Harlan) or C57BL/6J $\times 129$ SvJ background male mice (when specified) were used for miRNA profiling after stress. Adult male C57BL/6 mice were used for the miR-34 overexpression experiments. All mice, aged 11-16 weeks at the beginning of experiments, were kept on a $12 \mathrm{~h} \mathrm{light/dark}$ cycle, with food and water available ad libitum. Animals were handled according to approved protocols and animal welfare regulations of the Weizmann Institute of Science Ethics Committee.

\section{Acute restraint stress and chronic social defeat stress}

For the acute restraint stress, male mice were introduced into a perforated $50 \mathrm{ml}$ conical tube for $30 \mathrm{~min}$ as described previously (NeufeldCohen et al., 2010a), and brains were dissected $90 \mathrm{~min}$ after stress initiation. To induce chronic social defeat stress, 8-week-old C57BL/6 mice were subjected to a social defeat protocol as described previously (Elliott et al., 2010) and based on the study of Krishnan et al. (2007). Briefly, mice were placed in the home cage of an aggressive ICR mouse, and they physically interacted for $5 \mathrm{~min}$. During this time, the ICR mouse attacked the intruder mouse, and the intruder displayed subordinate posturing. A perforated clear Plexiglas divider was then placed between the animals, and they remained in the same cage for $24 \mathrm{~h}$ to allow sensory contact. The procedure was then repeated with an unfamiliar mouse for each of the next $10 \mathrm{~d}$. Brains were dissected 2 weeks after the last day of defeat procedure.

\section{Lentiviral vectors design and production}

miR-34c overexpression vectors were cloned as follows: the enhanced form of human synapsin I promoter (Hioki et al., 2007) was PCR amplified (forward primer, ttttttatcgatctcgagtagttattaatagtaatc; reverse primer, tttttaccggtggcgcgccegccgcagcgcagatggt) from pENTR1A-E/SYN-GFPWRPE1 (kindly provided by Dr. Takeshi Kaneko, Department of Morphological Brain Science, Graduate School of Medicine, Kyoto University, Kyoto, Japan) and inserted between $\mathrm{ClaI}$ and AgeI restriction sites to replace the CMV promoter in pCSC-SP-PW-IRES/green fluorescent protein (GFP) (kindly provided by Dr. Inder Verma, The Salk Institute for Biological Studies, La Jolla, CA). The miR-34c-EGFP sequence was cut from pEGFP-N1-miR-34c (see below, Luciferase assay constructs) plasmid and ligated into pCSC-Esyn-IRES/GFP using BamHI and BsrGI, replacing the original IRES/GFP sequence (as a control, EGFP was cut from pEGFP-N1 using BamHI and BsrGI to replace the IRES/GFP sequence).

sdCre (Pfeifer et al., 2001) or GFP viral constructs have been kindly provided by Dr. Inder Verma. High-titer ( $10^{9}$ viral particles/ml) lentiviruses were produced as described previously (Tiscornia et al., 2006). In brief, recombinant lentiviruses were produced by transient transfection in HEK293T cells. Infectious particles were harvested at 48 and $72 \mathrm{~h}$ after transfection, filtered through $0.45 \mu \mathrm{m}$ pore cellulose acetate filters, concentrated by ultracentrifugation, redissolved in sterile HBSS, aliquoted, and stored at $-80^{\circ} \mathrm{C}$.

\section{Stereotactic intracranial injection}

A computer-guided stereotaxic instrument and a motorized nanoinjector (Angle Two Stereotaxic Instrument; myNeurolab) were used. Mice were anesthetized using ketamine (100 mg/kg)/acepromazine ( $4 \mathrm{mg} / \mathrm{kg}) /$ xylazine $(10 \mathrm{mg} / \mathrm{kg})$ mix administered intraperitoneally and placed on a stereotaxic apparatus. One microliter of the lentiviral preparation was delivered to each central amygdala using a Hamilton syringe connected to a motorized nanoinjector system at a rate of $0.2 \mu \mathrm{l} / \mathrm{min}$ [coordinates relative to bregma: anteroposterior (AP),$-1.58 \mathrm{~mm}$; mediolateral (ML), $\pm 3.52 \mathrm{~mm}$; dorsoventral (DV), $-5.05 \mathrm{~mm}$, based on a calibration study indicating these coordinates as leading to the CeA in Dicer ${ }^{\text {flox/flox }}$ strain; and $\mathrm{AP},-1.22 \mathrm{~mm}$; ML, $\pm 2.6 \mathrm{~mm}$; DV,$-4.75 \mathrm{~mm}$ leading to the CeA in C57BL/6J strain]. Mice were subjected to behavioral studies after a 2 week recovery period.

\section{Tissue preparation and immunohistochemistry}

Animals were anesthetized with chloral hydrate $(1.4 \mu \mathrm{g} / \mathrm{g}$ body weight, i.p.) and perfused transcardially with $10 \mathrm{ml}$ of PBS, followed by $100 \mathrm{ml}$ of $2.5 \%$ paraformaldehyde. PFA fixed brains were postfixed in $2.5 \%$ PFA + $30 \%$ sucrose for $>24 \mathrm{~h}$ before sectioning. Sequential $30 \mu \mathrm{m}$ microtome coronal sections were collected and stored in $4^{\circ} \mathrm{C}$ PBS.

For GFP immunostaining, we used biotinylated anti-GFP antibody raised in rabbit as primary antibody (Abcam) and streptavidinconjugated Cy2 for secondary detection (Jackson ImmunoResearch). In a few cases, some infected cells were also detected in regions outside the $\mathrm{CeA}$, such as the basolateral amygdala (BLA), internal and external capsules, and basal ganglia. For NeuN immunostaining, we used anti NeuN antibody raised in mouse, with M.O.M. blocking and diluent reagents according to the instructions of the manufacturer (Vector Laboratories). Cy3 anti-mouse (Jackson ImmunoResearch) was used as a secondary antibody for NeuN staining. Nuclei were stained using $1.62 \mu \mathrm{m}$ Hoechst 33342 trihydrochloride, trihydrate (Invitrogen). For glial fibrillary acidic protein (GFAP) immunostaining, we used anti-GFAP antibody raised in rabbit as primary antibody (Dako), and streptavidin-conjugated $\mathrm{Cy} 3$ for secondary detection (Jackson ImmunoResearch). Calculation of GFAP intensity was similar to reported previously (Haramati et al., 2010). NIH ImageJ Software (National Institutes of Health, Bethesda, Maryland; http://imagej.nih.gov/ij/) was used to quantify GFAP intensity in identical rectangular areas encompassing the infected region, in three amygdala sections per mouse ( $n=4$ per group).

\section{Calculation of cellular density after sdCre versus GFP infection}

Three animals with the highest infection rate in each group (CeA-sdCre or CeA-GFP) were selected for this analysis. Two to five $30-\mu \mathrm{m}$-thick slices were selected from each brain for the quantification. Sections were labeled using anti-GFP antibody to label infected cells and Hoechst to label nuclei (as reported in the immunohistochemistry section). The infected region was defined using the anti-GFP fluorescence, and Hoechst-labeled nuclei were counted only within the borders of this region. Cell density was calculated as number of nuclei counted per infected area (300-1000 nuclei per infected region per slice were counted, and volume was calculated by considering slice thickness and area of infection per slice). Cell density was averaged within animal, and Student's $t$ test was computed between the two groups of $n=3$ mice. Cell counts are presented as $\times 10,000$ cells $/ \mathrm{mm}^{3}$.

\section{Primary cortical and amygdalar culture}

Embryos separated from the uterus of a female mouse carrying both conditional Dicer alleles (Dcr flox/flox $)$ and conditional R26R-YFP reporter alleles, were decapitated, and brains were isolated. Cortices and amygdalae were dissected and collected into HBSS medium containing trypsin. The tissue was mechanically dissociated, and cells were plated on poly-L-lysine-coated $(15 \mathrm{mg} / \mathrm{ml}) 13 \mathrm{~mm}$ round glass coverslips in 24-well culture plates, containing MEM with $10 \%$ serum. Several hours after plating, the medium was replaced with Neurobasal medium supplemented with B27 (Invitrogen). Culture was grown for 2 weeks, to obtain mature culture before infecting with sdCre-expressing lentiviruses. Ten microliters of concentrated virus were added to each well in $250 \mu \mathrm{l}$ of growth medium. At $6 \mathrm{~h}$ after infection, $600 \mu \mathrm{l}$ of growth medium was added to each well.

Amygdala punches

Mice were decapitated, and brains were released into a metal $1 \mathrm{~mm}$ brain matrix. Stainless-steel-coated single-edge blades were inserted into rele- 
A
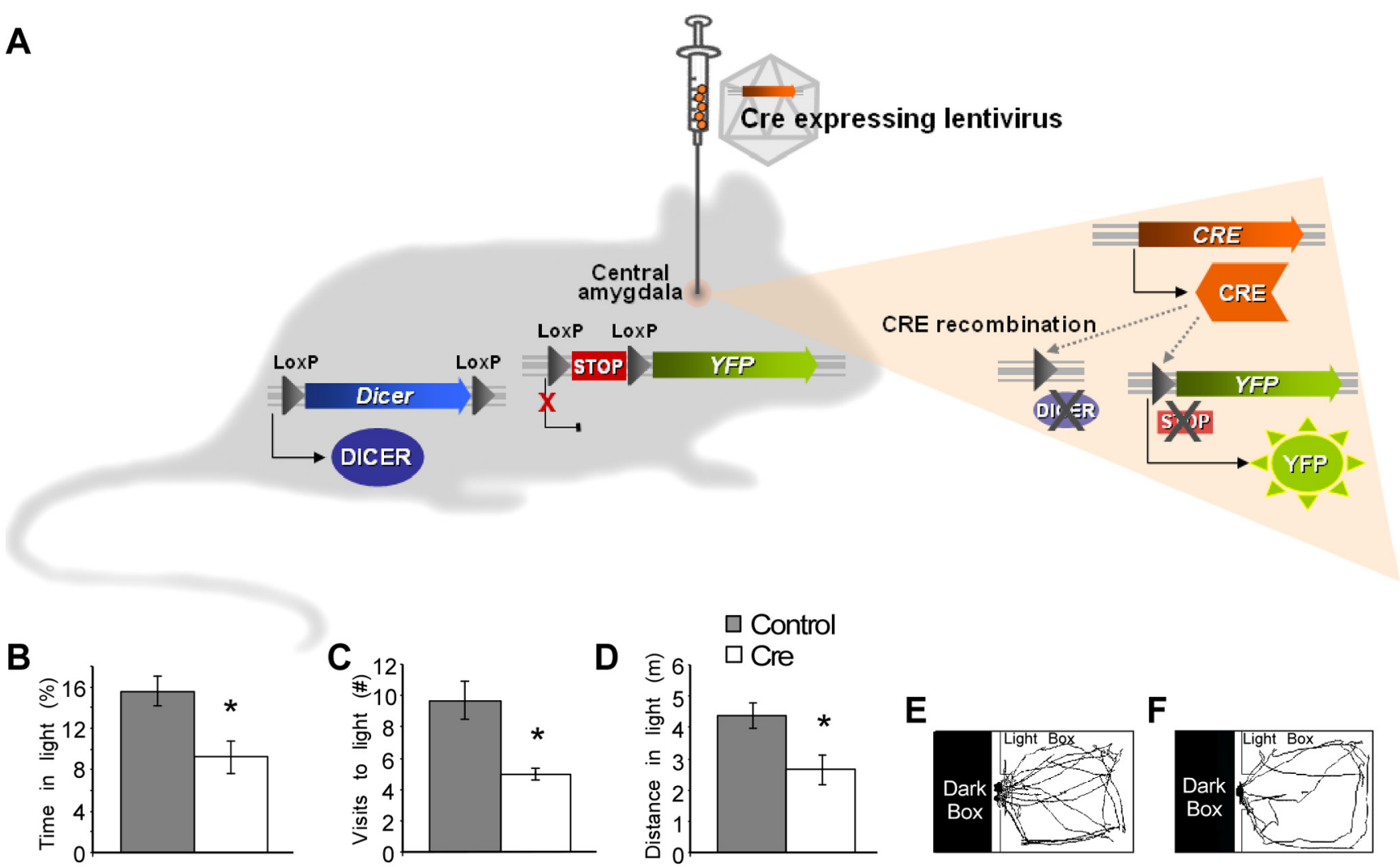

E

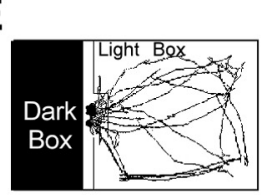

$\mathbf{F}$
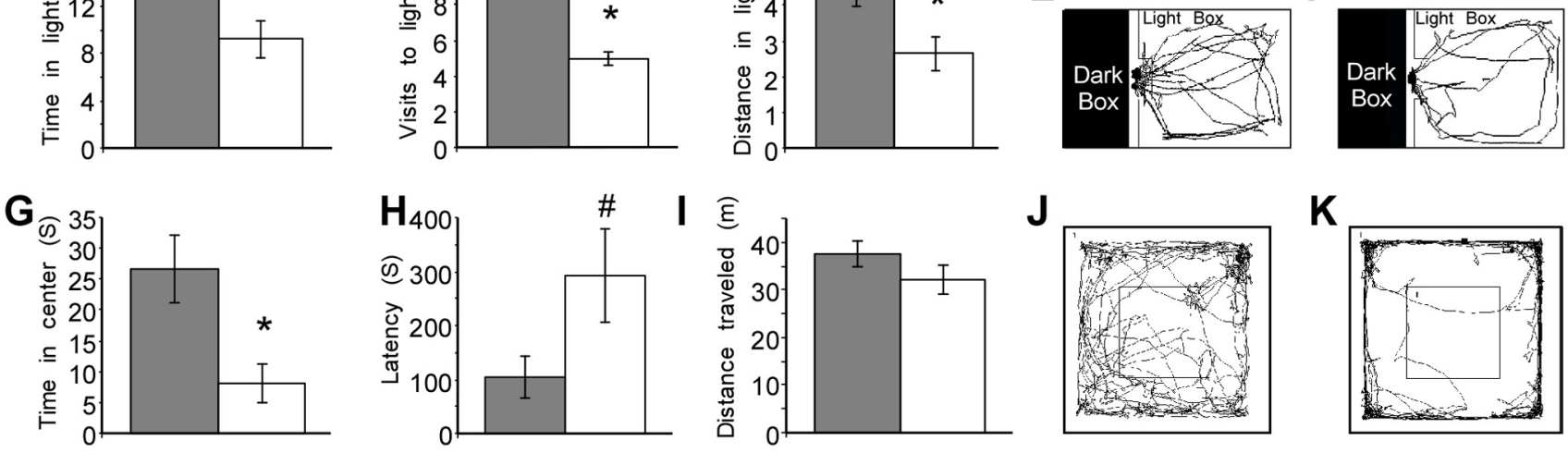

$\mathbf{L}$

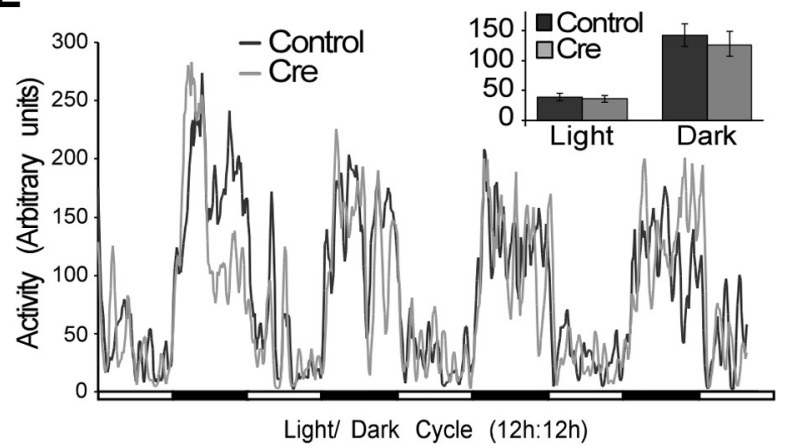

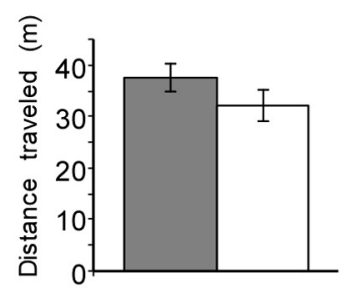

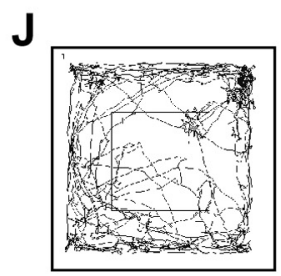

K

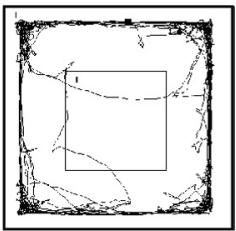

M

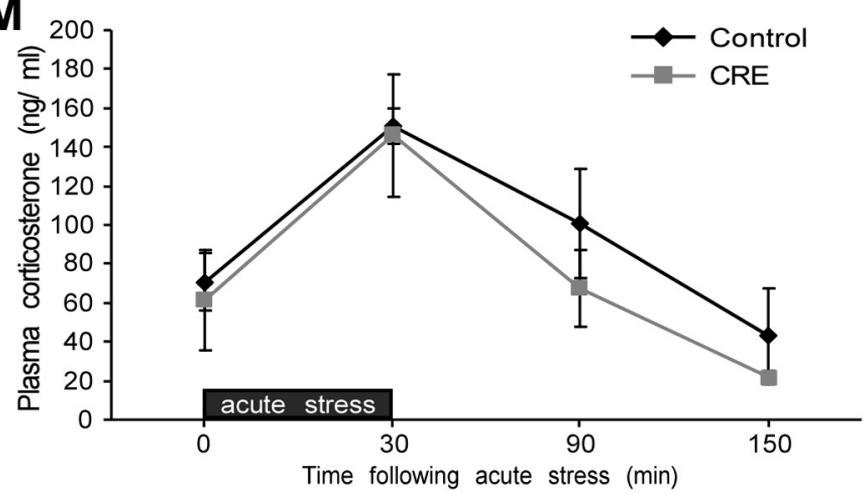

Figure 1. In vivo depletion of Dicer in mice central amygdala leads to an increase in anxiety-like behavior. $A$, Schematic representation of site-specific deletion of Dicer in the CeA using conditional Dicer mouse model and a lentiviral-mediated Cre expression. Lentiviruses expressing sdCre were injected into the CeA of mice carrying both floxed-dicer and floxedtranscriptional "stop"-YFP alleles at the age 9-10 weeks. Infected cells in the amygdala undergo (re-mediated recombination of loxP sites, leading to the ablation of Dicer gene and the induction of YFP expression. In the dark/light transfer test, two-tailed Student's $t$ test revealed that CeA-DCR-KO mice $(n=7)$ spent significantly less time in light $(\boldsymbol{B})$, visited the illuminated chamber significantly fewer times $(\boldsymbol{C})$, and traveled a significantly shorter distance in the light chamber compared with CeA-GFP controls $(\boldsymbol{D})(n=7)$. $\boldsymbol{E}, \boldsymbol{F}$, Representative traces of CeA-GFP control (E) and CeA-DCR-KO $(\boldsymbol{F})$ activity in the DLT as recorded by the VideoMot system (TSE Systems). In the open-field test, two-tailed Student's $t$ test revealed that CeA-DCR-KO mice $(n=6)$ spent significantly less time in the center of the OF arena $(\boldsymbol{G})$ and had a tendency toward longer latency to enter the center compared with CeA-GFP controls $(\boldsymbol{H})(n=6)$, whereas total distance traveled in the OF arena was not affected $(\boldsymbol{I})$. $\boldsymbol{J}, \boldsymbol{K}$, Representative traces of CeA-GFP control $(\boldsymbol{J})$ and CeA-DCR-KO $(\boldsymbol{K})$ activity in the $0 \mathrm{~F}$ arena as recorded by the VideoMot system (TSE Systems). L, Home-cage locomotion is similar for CeA-DCR-K0 and CeA-GFP mice. Insets represent average light- or dark-phase locomotion over $4 \mathrm{~d}$ of testing (repeated-measures two-way ANOVA; dark, $p=0.91$; light, $p=0.45$ ). All behavioral tests were administered $2-7$ weeks after viral injection. $\boldsymbol{M}$, Plasma corticosterone levels as measured by ELISA under basal conditions ( 0 ) and 30, 90, and 150 min after acute restraint stress ( $n=4$ and 5 , (re and control, respectively). DCR, Dicer. Bars represent mean \pm SEM. ${ }^{*} p<0.05,{ }^{\#} p<0.1$. 
vant slits $2 \mathrm{~mm}$ apart and pulled with brain slice mounted. Punches were taken from slightly frozen slices using a blunt-end micro dissecting needle of desired diameter (14 gauge), released into an Eppendorf tube and immediately frozen on dry ice. Punches were kept at $-80^{\circ} \mathrm{C}$ and further processed for RNA extraction.

\section{Total RNA extraction}

Total RNA was isolated using miRNeasy kit (Qiagen) to preserve miRNAs. Frozen brain punches were transferred into lysis buffer and immediately homogenized. Neuronal primary cultures or N2a cell cultures were lysed in-well, on ice. Additional processing was done according to the recommendations of the manufacturer. RNA extracts were stored at $-80^{\circ} \mathrm{C}$ until use.

\section{miRNA Array}

miRNA differential expression was assayed by Agilent or Affymetrix miRNA microarrays, according to the instructions of the manufacturer. For the assessment of miRNA differential expression using the Agilent array, $100 \mathrm{ng}$ of total RNA per sample (three control samples and two acute stress samples) were each labeled and hybridized according to the instructions of the manufacturer. Arrays were scanned using an Agilent microarray scanner. The data were extracted using the Agilent Feature Extraction software version 9 and analyzed using Partek Genomics Suite (Partek). Data from the GeneView.txt files were subject to $\log$ transformation and quantile normalization. For the assessment of miRNA differential expression using the Affymetrix array, $1 \mu \mathrm{g}$ of total RNA per sample (two control samples and two acute stress samples) were each labeled and hybridized according to the instructions of the manufacturer. Arrays were scanned using an Affymetrix microarray scanner. The data were extracted using the Affymetrix scanner software and normalized using the default parameters of the Affymetrix miRNAQCtool software (background adjust-

ment, quantile normalization, log transformation, and threshold determination). The normalized data from the four files were imported into Partek Genomics software. Genes not presented in any of the microarrays were filtered out. Because of the difference in miRNA distribution, different log ratio cutoffs (corresponding to $\sim 1$ SE for each array) were chosen for each array: 0.2 for Agilent and 0.4 for Affymetrix. miRNAs with log ratios greater than the cutoff were compared between arrays, and the common miRNAs are reported.

\section{Behavioral paradigms}

All behavioral tests were performed during the dark phase of the circadian cycle as described previously (Neufeld-Cohen et al., 2010a,b; Kuperman et al., 2010; Sztainberg et al., 2010).

Open-field, dark/light transfer, and elevated plus maze tests. The openfield (OF) apparatus consists of a white Plexiglas box $(50 \times 50 \times 40 \mathrm{~cm})$ with a lamp directed to the center of the field providing a 120 lux illumination on the floor. Each mouse was placed in the corner of the apparatus to initiate a $10 \mathrm{~min}$ test session.

The dark/light transfer (DLT) test apparatus is a rectangular Plexiglas box divided by a partition into two environments: a dark compartment $(14 \times 27 \times 26 \mathrm{~cm})$ and a brightly illuminated (1000-1100 lux) light compartment $(30 \times 27 \times 26 \mathrm{~cm})$. The compartments are connected by a small passage in the bottom center of the partition. The mice were placed in the dark compartment to initiate the test session. All four paws must enter a compartment to qualify as a transfer. Each mouse was tested in a single 5 min session during the dark phase of the circadian cycle.

The elevated plus maze (EPM) apparatus consists of a gray polyvinyl chloride maze, comprising a central part $(5 \times 5 \mathrm{~cm})$, two opposing open arms $(30.5 \times 5 \mathrm{~cm})$, and two opposing closed arms $(30.5 \times 5 \times 15 \mathrm{~cm})$. The apparatus was elevated to a height of $53.5 \mathrm{~cm}$, and the open arms were illuminated with 6 lux. Mice were placed in the center, facing an open arm to initiate a $5 \mathrm{~min}$ test session. The distance traveled and the time spent in the open arms were measured.

Behaviors were recorded using a camera mounted above the apparatus and analyzed by TSE software VideoMot2 (TSE Systems).

Home-cage locomotion. Locomotor activity was examined over a $96 \mathrm{~h}$ period, which proceeded several days of habituation. Mice were single housed in specialized home cages, and locomotion was measured using an infrared-based automatic system (InfraMot; TSE Systems).

\section{Corticosterone measurements}

Plasma corticosterone levels were measured by ELISA as described previously (Neufeld-Cohen et al., 2010a). New cohorts of AMY-DCR-KO and control mice were single housed $24 \mathrm{~h}$ before testing. Tail blood (20 $\mu \mathrm{l})$ was collected under basal "no-stress" condition and at several time points $(30,90$, and $150 \mathrm{~min}$ ) after initiation of acute $30 \mathrm{~min}$ restraint stress (by introduction into a ventilated $50 \mathrm{ml}$ tube). Bleeding was induced by cutting the tip of the tail, and blood was collected by a desig- 

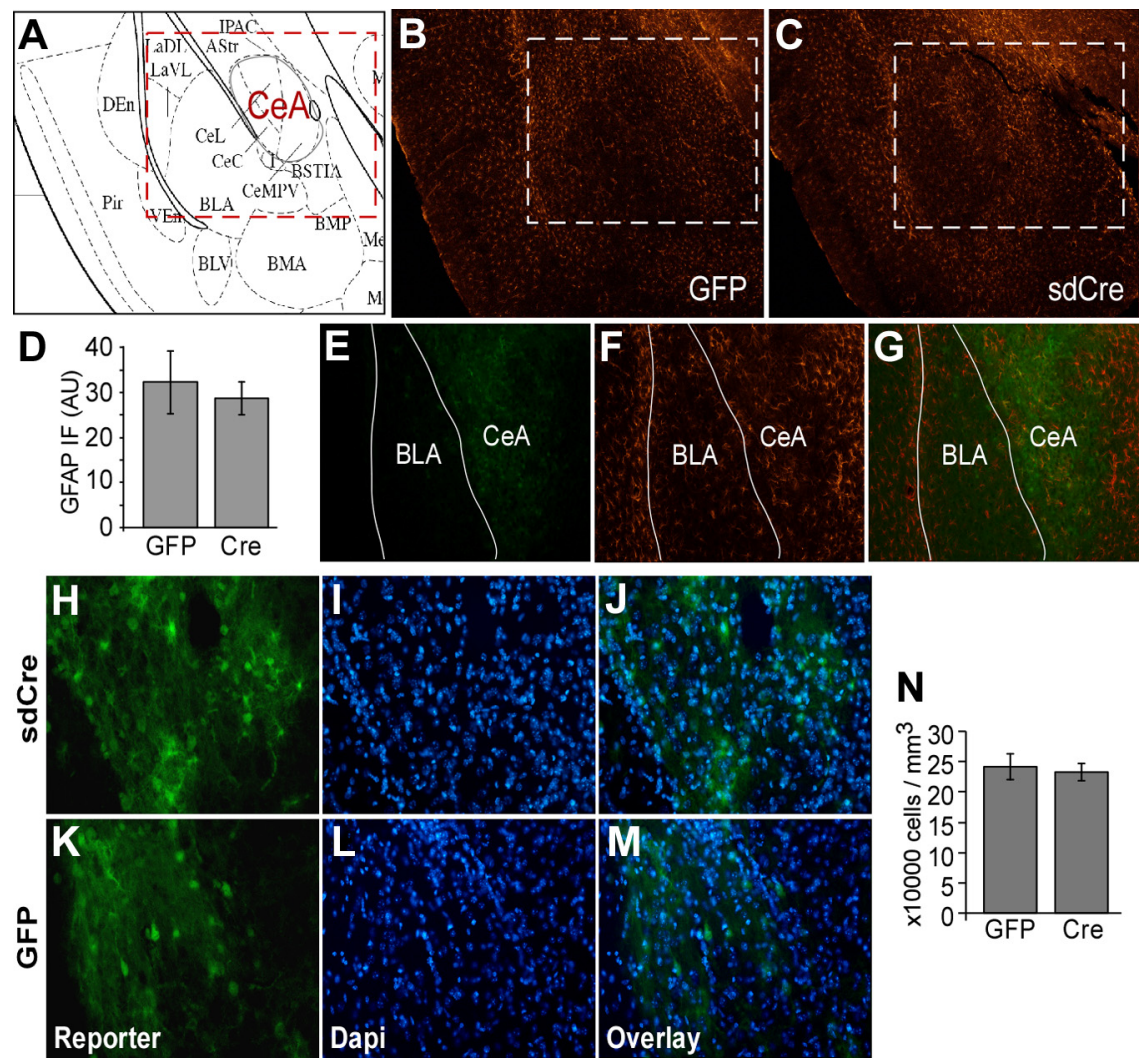

Figure 3. CeA neurons survive 8 weeks after sdCre expression. $\boldsymbol{A}-\boldsymbol{C}$, Representative infection sites for GFP $(\boldsymbol{B})$ and $\mathrm{LV}$-sdCre $(\boldsymbol{C})$ immunostained for GFAP. D, GFAP immunoreactivity quantification in the region represented by a dashed rectangle in $\boldsymbol{A}-\boldsymbol{C}$. $\boldsymbol{E}-\boldsymbol{G}$, Region of dense sdCre infection immunostained for GFP $(\boldsymbol{E})$ and GFAP $(\boldsymbol{F})$. $\boldsymbol{G}$, Overlay of $\boldsymbol{E}$ and $\boldsymbol{F}$. $\boldsymbol{H}-\boldsymbol{M}$, Representative infection sites for LV-sdCre injection $(\boldsymbol{H}-\boldsymbol{J})$ and LV-GFP injection $(\boldsymbol{K}-\boldsymbol{M})$. $\boldsymbol{N}$, Quantification of cell density (Hoechst-positive nuclei/tissue volume) in the region infected by sdCre and GFP.

nated pipette into an Eppendorf tube containing $5 \mu \mathrm{l}$ of $0.5 \mathrm{M}$ EDTA, $\mathrm{pH}$ 8.0 , and kept on ice. Plasma was separated by centrifugation and kept at $-20^{\circ} \mathrm{C}$ until use. Two microliters of plasma per sample were used for measurement. Plasma corticosterone levels were measured by ELISA (Cayman Chemical Company) according to the instructions of the manufacturer.

\section{Primers for $m R N A R T$-PCR}

The following primers were used: corticotropin releasing factor receptor type 1 (CRFR1) RT-qPCR oligonucleotide primers, 5' -TGCCAGGAGATTCTCAACGAA- $3^{\prime}$ and $5^{\prime}$-AAAGCCGAGATGAGGTTCCAG-3'; CRFR2 RT-qPCR oligonucleotide primers, 5'-TACCGAATCGCCCTCATTGT-3' and 5'-CCACGCGATGTTTCTCAGAAT-3'; HPRT RT-qPCR oligonucleotide primers: 5'-GCAGTACAGCCCCAAAATGG-3' and 5'-GGTCCTTTTCACCAGCAAGCT-3'; Dicer oligonucleotide primers, 5'CACGCCTCCTACCACTACAACA- $3^{\prime}$ and $5^{\prime}$-CCTGGAGAATGCTGCCGTGGGT-3'.

Intensities of Dicer and S16 DNA bands were calculated using NIH ImageJ Software. Dicer expression levels were normalized to S16 levels.

\section{miRNA RT-qPCR expression analysis}

Quantitative miRNA expression was acquired and analyzed using an $A B$ 7500 thermocycler (Applied Biosystems). RNA samples were assayed using miScript reverse transcription kit and SYBRGreen PCR kit (Qiagen) according to the guidelines of the manufacturer. U6 snRNA was used as an internal control.

Each of the following oligonucleotide primers was used in addition to the universal primer supplied with the miScript kit (Qiagen): miR-34c, 5'-AGGCAGTGTAGTTAGCTGATTGC-3'; miR-34a, 5' -TGGCAGTGTCTTAGCTGGTTGT-3'; miR-15b, 5' -TAGCAGCACATCATGGTTTACA-3'; miR-100, 5'-AACCCGTAGATCCGAACTTGTG-3'; miR-92a,

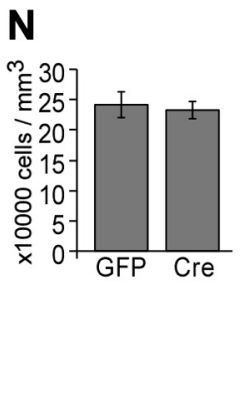

5'-TATTGCACTTGTCCCGGCCTG-3'; and U6 snRNA, 5'-GATGACACGCAAATTCGTGAA-3'.

miRNA upregulation in vivo is presented as fold change relative to the no-stress control group or to the GFP-infected control group. miR-34c upregulation in cells is presented as fold change relative to GFP transfection/infection (because HEK293T and N2a cells appear to endogenously express very low levels of miR-34c, fold change relative to control is robustly enhanced yet reflects similar overall levels to those overexpressed in vivo).

Luciferase assay constructs and procedure Cloning of miR-34c/a into pEGFP-N1. PremiRNA DNA fragment was PCR amplified from mouse genomic DNA using primers that include AgeI overhangs: pre-miR-34c, 5'-GGGCACCGGTCATATGGGCAGCGACTAGAGTCAACC-3' and 5'-GGGCACCGGTCCCAAACCACTAATAGTATGGTAAGAA-3'; pre-miR34a, 5' -CGCGACCGGTCATATGATCTTTCTCCCGCAGCCTCT-3' and 5'-CCGCACCGGTGCATCCCATACCCACCAGTA-3'. PCR fragment was inserted in a single AgeI site between the CMV promoter and EGFP coding sequence in the pEGFP-N1 vector (Clontech). Cloning orientation was verified by diagnostic cuts followed by sequencing.

Cloning of $3^{\prime}$ UTRs into PsiCHECK2 luciferase expression plasmid. CRFR1-3' UTR sequence was PCR amplified from mouse genomic DNA (primers: 5' -TTCCACAGCATCAAGCAGTC-3' and $5^{\prime}$-CCCAGCAGAGTGAACGTCTT-3'). PCR fragment was ligated into $\mathrm{pGem}-\mathrm{T}$ easy vector (Promega) according to the guidelines of the manufacturer and further subcloned into a single NotI site at the $3^{\prime}$ end of luciferase in the PsiCHECK2 reporter plasmid (Promega). Cloning orientation was verified by diagnostic cuts followed by sequencing. A mutated form of CRFR1-3' UTR lacking all 8 bases of miR-34 conserved seed-match sequence was established by generating two partially complementary PCR fragments, used as templates for ligation PCR (primers: 5'-GGATTTCATCAGCACTGTGGATCCTGGAAAGCCCTGCCTTG-3' and '5'-CAAGGCAGGGCTTTCCAGGATCCACAGTGCTGATGAAATCC- 3 ' , each used with one of the aforementioned primers). The mutated PCR fragment lacks all 8 bases of miR- 34 conserved seed-match sequence and includes a new BamHI restriction site to facilitate diagnostics. It was further cloned as described for the intact form.

Transfections and luciferase assay in HEK293T cells. Cells were grown on poly-L-lysine in 24 -well format to a $70-85 \%$ confluency and transfected using polyethyleneimine or Lipofectamine with the following plasmids: 10 ng of psiCHECK-2-3' UTR plasmid and 430 ng of pEGFPmiR-34c or empty pEGFP overexpression plasmids. At $48 \mathrm{~h}$ after transfection, cells were lysed, and luciferase reporter activity was assayed as described previously (Chen et al., 2005). Renilla luciferase values were normalized to control firefly luciferase levels (transcribed from the same vector but not affected by $3^{\prime}$ UTR tested) and averaged across three- to eight-well repetitions per condition. Data presented are the average of two experiments.

Infections, transfections, and luciferase assay in N2a cells. N2a cells were infected in single wells of 24-well plates, with $10 \mu \mathrm{l}$ of concentrated viruses (either LV-E/syn-miR-34c, LV-E/syn-miR-34a or LV-EsynEGFP) in $250 \mu \mathrm{l}$ of growth medium. At $6 \mathrm{~h}$ after infection, $600 \mu \mathrm{l}$ of growth medium was added to each well. Cells were passaged and underwent a second cycle of infection to achieve a stable line with high infection efficiency. For transfection, cells were grown on poly-L-lysine in 24 -well plates to a $70-85 \%$ confluency and transfected using Lipofectamine 2000 (Invitrogen) with the following plasmids: $600 \mathrm{ng}$ of 
cAMP-RE-Luciferase (kindly provided by Marc Montminy, The Salk Institute for Biological Studies, La Jolla, CA) and $50 \mathrm{ng}$ of pRL-Elf1 as a normalizer (Control Renilla Vector modified from Promega). At $24 \mathrm{~h}$ after transfection, cells were treated in DMEM with either $0.1 \%$ BSA or CRF $(314,157$, and $31.4 \mathrm{~nm})$ in $0.1 \%$ BSA for $5 \mathrm{~h}$. After treatment, cells were lysed, and luciferase reporter activity was assayed as described previously (Chen et al., 2005; Kuperman et al., 2011). Firefly luciferase values were normalized to Renilla luciferase levels (transcribed by the general Elf1 promoter, which was not affected by the CRF treatment) and averaged across three well repetitions per condition.

\section{Statistical analysis}

Data are expressed as mean \pm SEM. Statistical significance was determined by two-tailed Student's $t$ test or two-way ANOVA followed by post hoc Student's $t$ test when specified. Asterisks representing post hoc comparisons are presented in figures only when interaction between variables is significant $(p<0.05)$ or near significant $(p<0.1)$ after ANOVA.

\section{Results}

In vivo depletion of Dicer in mice central amygdala leads to an increase in anxiety-like behavior

To examine the possible role of amygdalar miRNAs in mediating behavioral changes associated with the central stress response, we studied the effect of miRNA depletion in the CeA of adult mice, on anxiety-like behavior. Dicer-1 is an RNAseIII-containing protein, essential for the biogenesis of most mature miRNA (Babiarz et al., 2008). Although at least one study reported Dicer as nonessential for specific miRNA processing (Cheloufi et al., 2010), Dicer is widely accepted as a key regulator for mature miRNA biogenesis and by genetically deleting Dicer, cells can be effectively depleted of most mature miRNAs (Harfe et al., 2005). The half-life of miRNAs in neurons varies; some miRNAs are reported to have short turnover (Krol et al., 2010b), whereas others seem to have a long turnover time (van Rooij et al., 2007; for review, see Leung and Sharp, 2010). Several conditional Dicer knock-out mouse models have demonstrated the role of miRNAs in neural development, differentiation, and survival (Kim et al., 2007; Schaefer et al., 2007; Cuellar et al., 2008; Davis et al., 2008; De Pietri Tonelli et al., 2008; Dugas et al., 2010; Haramati et al., 2010; Li and Jin, 2010; Zhao et al., 2010). Nevertheless, such models do not allow examination of the role of miRNA, specifically in adult brain structures. Interestingly, a recent study reported mice exhibiting enhanced memory performance after tamoxifen-induced Dicer ablation in the adult forebrain, whereas signs of cell death could be identified only 20 weeks after tamoxifen-induced Cre activation (Konopka et al., 2010). To delete Dicer specifically in cells of the adult central amygdala, we produced high-titer lentiviruses expressing either sdCre (Pfeifer et al., 2001) or GFP as a control lentivirus. Lentiviruses expressing sdCre were injected intracranially and bilaterally into the CeA of adult male mice carrying conditional Dicer alleles (Harfe et al., 2005; Dcr ${ }^{\text {flox/flox }}$; Fig. $1 A$ ). This version of sdCre enables only a transient expression of Cre-recombinase, minimizing Creinduced toxicity (Pfeifer et al., 2001). R26R-YFP reporter alleles (Srinivas et al., 2001) in the genetic background of this mouse line enabled the detection of Cre-mediated recombination by the induction of YFP expression (Fig. 1A). Dcr ${ }^{\text {flox/flox }}$ littermates injected with GFP-expressing lentiviruses served as controls. After 2 weeks of recovery, mice were tested for anxiety-like behavior using the DLT and OF tests. To eliminate locomotor deficits as an explanation for possible differences, we subsequently determined the locomotor behavior in the home cage across the circadian cycle. Only mice with histological examination confirming infection predominantly in the CeA (Fig. 2C) were included in the analysis. Mice injected with sdCre-expressing lentiviruses into
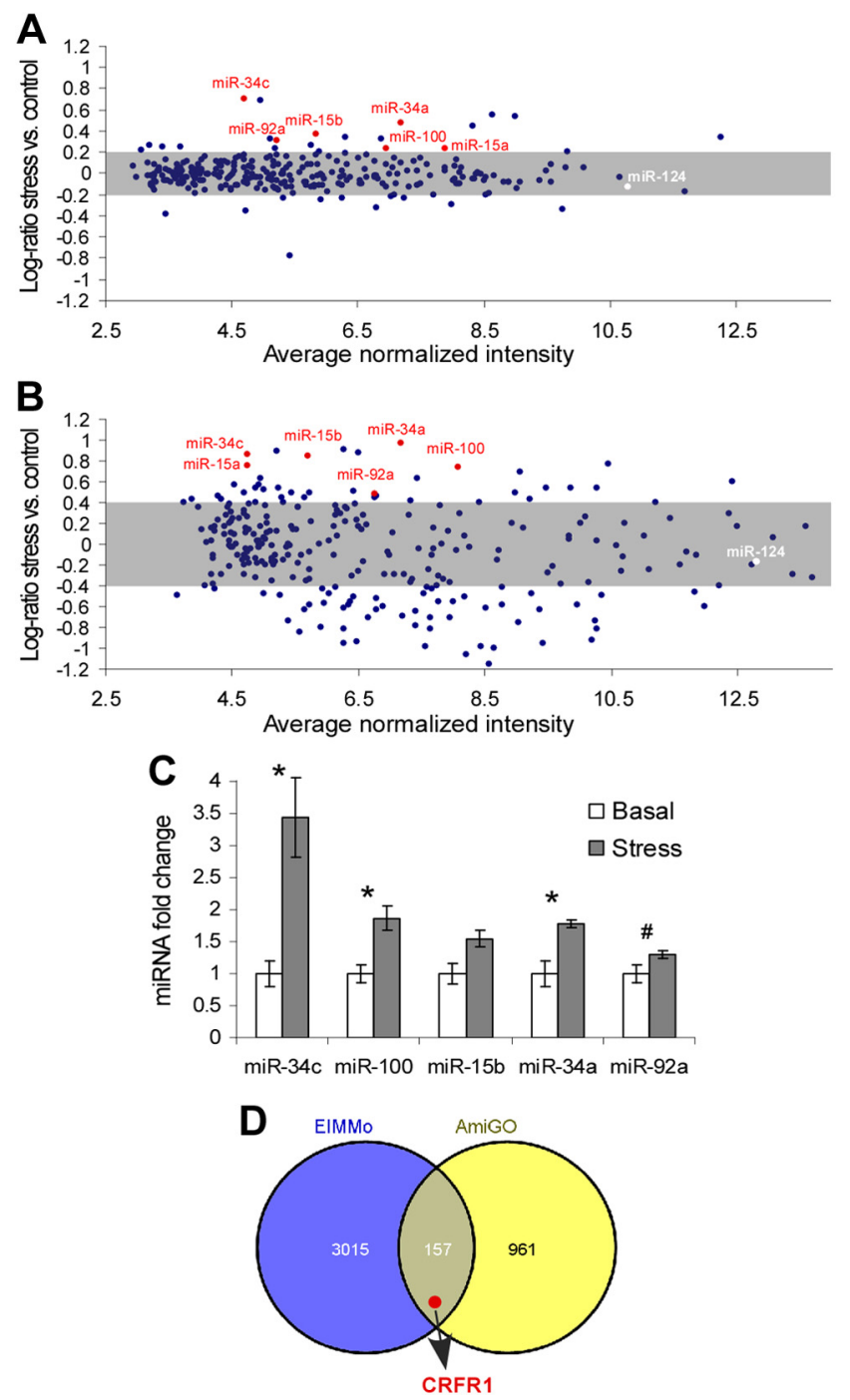

Figure 4. Differential expression of miRNAs in the amygdala 90 min after acute stress. $\boldsymbol{A}$ Agilent array results. $\boldsymbol{B}$, Affymetrix array results. Normalized values are depicted as $\log 2$ ratio (stress vs control) of spot intensity plotted against average intensities across conditions ( $n=2$, 2). The intensity of each miRNA was calculated as the average normalized intensity across biological repeats. miR-100, miR-15a, miR-15b, miR-34a, miR-34c, and miR-92a are indicated in red. miR-124, a well-established neuronal marker not affected by the stress protocol, is indicated in white. C, qRT-PCR for selected miRNA. ${ }^{*} p<0.05$; $" p<0.1$. D, Stress-responserelated predicted targets of miRNAs upregulated by stress. One hundred fifty-seven genes are common to ElMMo search for upregulated miRs and AmiG0 "response to stress" annotation. Venn diagram created using Venny (http://bioinfogp.cnb.csic.es/tools/venny/index.html).

the CeA (CeA-DCR-KO) showed a significant increase in anxiety-like behavior compared with control mice that were injected with GFP-expressing lentiviruses (CeA-GFP). In the DLT test, CeA-DCR-KO mice spent significantly less time in light (Fig. $1 B$ ), visited the illuminated chamber significantly fewer times (Fig. $1 C, E, F$ ), and traveled a significantly shorter distance in the light chamber (Fig. 1D-F) compared with CeA-GFP controls. In the OF test, CeA-DCR-KO mice spent significantly less time in the center of the arena (Fig. $1 G, J, K$ ) and showed higher latency to enter the center (Fig. $1 H$ ) compared with CeA-GFP controls. CeA-DCR-KO mice showed normal general locomotion compared with CeA-GFP controls, as inferred from total distance parameter in the OF test (Fig. $1 I$ ) and from their homecage locomotion (Fig. $1 \mathrm{~L}$ ). Collectively, these results suggest that 

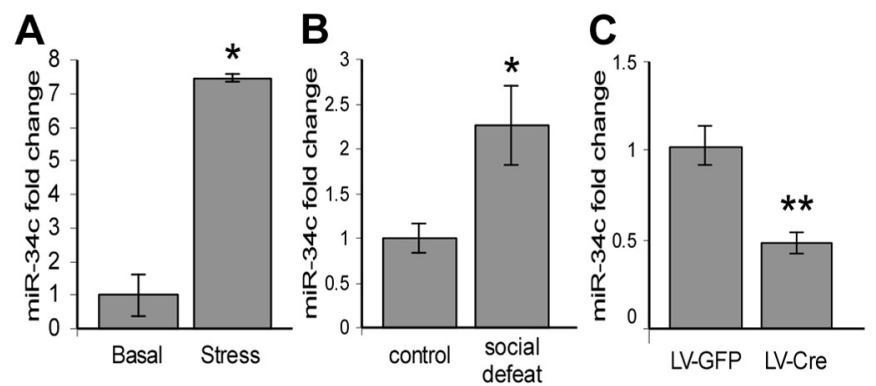

D
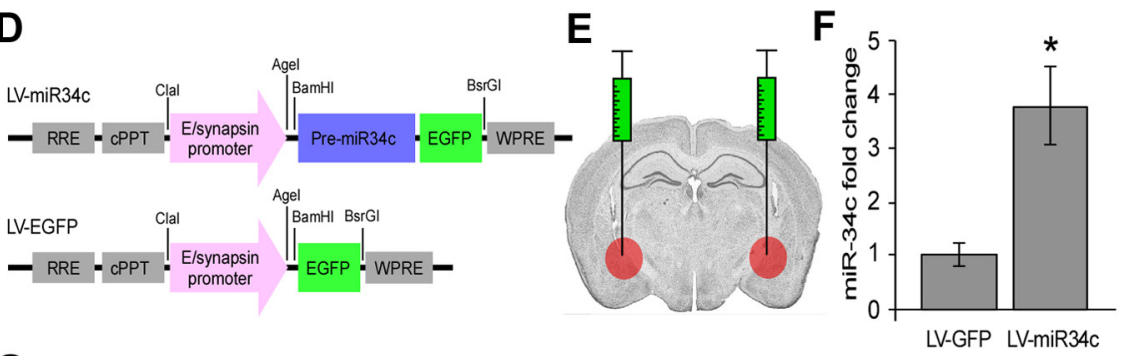

G

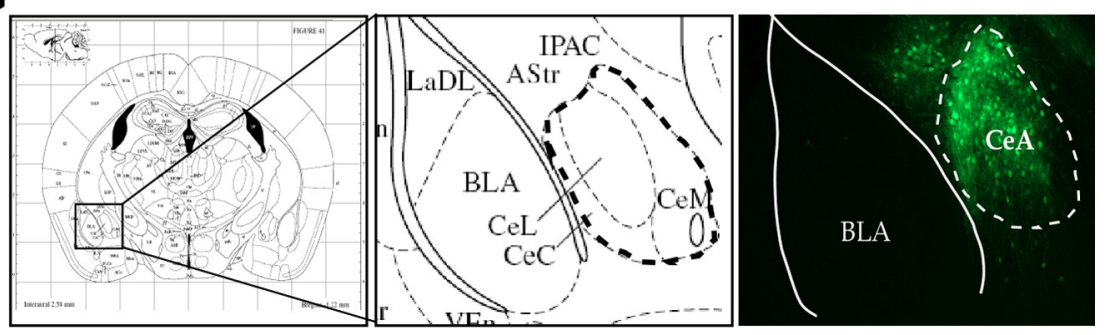

Figure 5. miR-34c overexpression in the CeA. $A, R T-q P C R$ showing miR-34c upregulation 90 min after acute restraint stress in a group of mixed background mouse strain ( $n=2$ and 2). $B$, RT-qPCR showing miR-34c upregulation 2 weeks following $10 \mathrm{~d}$ of daily social defeat stress $(n=15$ and 6). C, miR-34c downregulation in the DCR-KO amygdala primary culture. D, Schematic representation of the lentiviral expression plasmids used for the production of LV-miR-34c and LV-EGFP. E, Illustration of LVmiR-34c and LV-EGFP injection sites. Red circles represent the punch area used for RNA extraction. $\boldsymbol{F}$, RT-qPCR verification of miR-34c overexpression in the amygdala $7 \mathrm{~d}$ after viral injection of LV-miR-34c relative to LV-EGFP control. Expression is presented as fold change relative to control levels ( $n=6$ and 4 punches, respectively). $\mathbf{G}$, Left, Schematic representation of site of delivery adapted from Paxinos and Franklin digital mouse brain atlas. Middle, Enlargement of the amygdala region corresponding to the injection site. Right, A representative microscope image of virally infected CeA, after behavioral studies. GFP expression was assessed using immunohistochemistry. RRE, Rev-responsive element; CPPT, central polypurine tract; WPRE, Woodchuck hepatitis posttranscriptional regulatory element. ${ }^{*} p<0.05$.

CeA miRNA processing is essential for an adequate behavioral stress response.

To better elucidate the affects of amygdalar Dicer ablation on the neuroendocrine stress response, we determined the hypothalamic-pituitary-adrenal (HPA) axis activity in AMY-DCR-KO and controls under both basal (prestress) and stress conditions. The basal morning corticosterone levels of CeA-DCR-KO mice revealed no significant difference compared with CeA-GFP control mice (Fig. 1M). To examine the response of the HPA axis to stress, CeA-DCR-KO and CeA-GFP controls were subjected to $30 \mathrm{~min}$ of restraint stress and the corticosterone levels were measured immediately after the stress and 90 and $150 \mathrm{~min}$ from stress initiation. No significant changes in stress-induced levels of corticosterone were observed between the groups (Fig. 1M).

\section{Histological examination of infected neurons}

Eight weeks after viral injection and after the behavioral and physiological examinations, mice were perfused intracardially and their brains were sectioned. Using the fluorescent reporters, lentiviral GFP for the controls, or recombination-induced YFP for sdCre infections, we confirmed the CeA infection localization (Fig. 2A-C). Because the sdCre-expressing lentiviral vectors do not carry a florescent reporter gene, any YFP expression observed in infected cells is a direct indication for sdCre function in these cells. Double staining for YFP and NeuN (a neuronal-specific nuclear protein) revealed dense CeA infection that consists of many infected neurons (positive for both NeuN and YFP). Nonneuronal cell types and uninfected neurons can also be found in the infection site (Fig. $2 D)$. A closer observation of isolated infected neurons (observed at the periphery of the infection site to allow for better detection of cell morphology) revealed that these cells survive and appear to exhibit normal gross morphology and arborization (Fig. $2 E-G)$. To further evaluate the neuronal morphology of neurons lacking Dicer, we prepared cortical primary culture from mice embryos carrying both conditional Dicer alleles (Dcr ${ }^{\text {flox/flox }}$ ) and conditional R26R-YFP reporter alleles. After 2 weeks of growth and establishment of mature culture, cells were infected with sdCreexpressing lentiviruses. Five days after sdCre introduction, neurons exhibited intact gross morphology (Fig. $2 H$ ). To verify that sdCreexpressing lentiviruses indeed cause the knock-out of Dicer in neurons derived from the Dcr ${ }^{\text {flox/flox }}$ mouse model, RNA was extracted from primary cultures 1 week after sdCre infection. Semiquantitative RT-PCR for Dicer mRNA demonstrated a marked decrease in Dicer mRNA expression in the sdCre-infected versus non-infected control cultures (Fig. $2 I, J$ ). It is notable that infection efficiency level was not $100 \%$ in these cultures, and therefore some Dicer mRNA could still be detected.

We further looked for signs of specific neurotoxicity caused by Dicer KO in adult $\mathrm{CeA}$ in the time frame examined ( 8 weeks after infection, after behavioral examination was completed). Infected brain sections were stained against GFAP. Some GFAP immunoreactivity was observed in the area surrounding the injection path, in both sdCRE and GFP lentiviral injections. However, no differences were found in GFAP immunoreactivity in infected CeA of AMY-DCR-KO mice and controls (Fig. 3A-D). Also, no elevation in GFAP immunoreactivity was observed in regions of dense LV-Cre infection (Fig. $3 E-G$ ). To further confirm that neither Cre toxicity nor lack of Dicer caused overt cell loss in the time frame examined, we quantified the density of cells in infected regions and found no difference in the density of Hoechst-stained nuclei (Fig. $3 H-N$ ). With these in vivo and in vitro data, we can cautiously speculate that the observed behavioral changes are mediated, at least in part, through changes in the regulation of neuronal genes associated with the behavioral response to stress and not by an induced cell death (in line with Konopka et al. 2010). Nonetheless, we cannot rule out all possible neurodegenerative changes caused by Dicer ablation in the amygdala at the time point of behavioral and histological examinations and that any of the behavioral changes observed may be secondary to such disruptions in CeA function. To further assess the possible contribution of miRNA to the central stress re- 
sponse, we continued with more direct approaches as described below.

\section{Differential expression of miRNAs in the amygdala after acute restraint stress and bioinformatics predictions of miRNAs target in stress-related genes}

To further support the physiological relevance of miRNAs in regulating the central stress response and to identify specific miRNAs that are involved in regulating stress-related genes, we explored miRNAs expression profile in the amygdala after exposure to acute restraint stress. Mice were subjected to restraint stress for $30 \mathrm{~min}$, and amygdalae were collected $90 \mathrm{~min}$ from stress initiation. RNA samples produced from frozen amygdala punches were hybridized onto two platforms of specialized miRNA microarray, namely Agilent and Affymetrix, and the relative expression of hundreds of miRNAs was directly compared. We found that, after acute restraint stress, miRNA expression pattern in the amygdala is altered, demonstrating up to threefold increase or decrease in the expression of several miRNAs (Fig. 4). Among the miRNAs most affected by restraint stress, six miRNAs (from four miRNA families), namely miR-15a, miR-15b, miR-34c, miR-34a, miR-92a, and miR-100, were found to be upregulated by the stress procedure across both Agilent (Fig. $4 A$ ) and Affymetrix platforms (Fig. $4 B$ ). These miRNAs were further examined using qRT-PCR (Fig. 4C). We next used the EIMMo3 database (http://www.mirz.unibas.ch/ElMMo3/, Swiss Institute of Bioinformatics, University of Basel, Basel, Switzerland) to search for putative targets for these miRNAs. The EIMMo3 search allows for limiting targets to those mRNAs that are expressed in the amygdala. This search yielded a total of $3172 \mathrm{pu}-$ tative targets for the aforementioned miRNAs. We then searched the AmiGO gene ontology database (Carbon et al., 2009) to find mouse genes annotated as related to the stress response and found 1118 mouse genes annotated under the term "response to stress" (accession number GO:0006950). One hundred fiftyseven transcripts appear in both lists. These common transcripts represent putative targets of those miRNAs upregulated by acute stress that are expressed in the amygdala and are annotated as stress response related (Fig. 4D). Eighty-five of these genes are bioinformatically targeted by the miR-34 family.

\section{Lentiviral-mediated overexpression of miR-34c in the CeA has anxiolytic properties}

Because miR-34c has confirmed the highest induction, of $\sim 3.5$ fold (Fig. 4C), we further assessed the robustness of this effect. We examined a second group of mice from a mixed background strain and indeed we confirmed miR-34c upregulation $90 \mathrm{~min}$ after stress (Fig. 5A). To examine the long-lasting effect, we explored the effect of chronic social defeat stress on miR-34c expression and found miR-34c upregulation 2 weeks after the end of a $10 \mathrm{~d}$ social defeat stress procedure (Fig. $5 B$ ). The upregulation of miR-34c levels in the amygdala after stress may be needed for mounting a proper stress response, may fulfill a longer-term coping mechanism, and/or be part of a homeostasis-promoting mechanism after a stressful experience. Interestingly, miR-34c levels were significantly downregulated in the DCR-KO amygdala cells (Fig. 5C). To examine the functional significance of miR-34c upregulation after stress, we cloned the mouse genomic sequence of pre-miR-34c downstream to the enhanced synapsin promoter (Hioki et al., 2007) and upstream to a GFP reporter to establish the lentiviral expression plasmid pCSC-E/ Syn-Pre-miR-34c-EGFP (Fig. 5D). We constructed the same plasmid without a miRNA sequence (pCSC-E/Syn-EGFP) to be
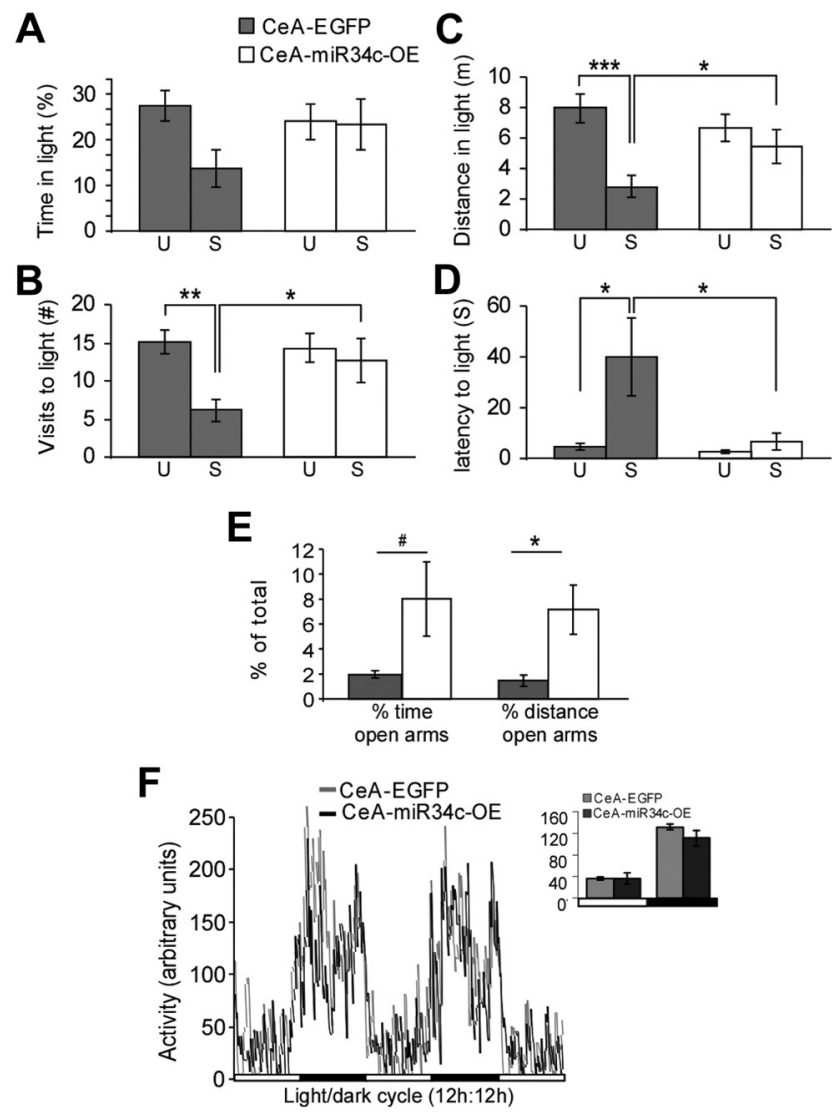

Figure 6. Over-expression of miR-34c in mice central amygdala has anxiolytic properties. $A-D$, In the dark/light transfer test, CeA-EGFP controls show indices of increased anxiety $24 \mathrm{~h}$ after acute restraint stress, whereas $C$ CA-miR-34c- 0 E mice behavior remains unaffected after stress (repeated-measures two-way ANOVA, asterisks represent post hoc Student's $t$ test comparisons). At $24 \mathrm{~h}$ after acute restraint stress, CeA-miR-34c-0E mice $(n=6)$ spent more time in light $(\boldsymbol{A})$, visited the illuminated chamber more $(\boldsymbol{B})$, traveled a significantly longer distance in the light chamber $(\boldsymbol{C})$, and showed a longer latency to enter the light chamber compared with CeA-EGFP controls ( $\boldsymbol{D})(n=6)$. $\boldsymbol{E}$, In the EPM test, CeA-miR-34c-0E mice traveled a significantly larger percentage of their overall distance in the open arms and spent more time in the open arms compared with CeA-EGFP controls. F, CeA-miR-34c-0E present normal home-cage locomotion compared with CeA-EGFP mice. Insets represent average light- or dark-phase locomotion over $2.5 \mathrm{~d}$ of testing. U, Unstressed; $\mathrm{S}, 24 \mathrm{~h}$ after stress. All behavioral tests were administered 2-7 weeks after viral injection. Bars represent mean \pm SEM. ${ }^{*} p<0.05 ;{ }^{* *} p<$ $0.01 ;{ }^{* *} p<0.005 ;{ }^{*} p<0.1$.

used as a control. With these constructs, we produced high-titer lentiviruses enabling neuronal-enriched overexpression of miR$34 \mathrm{c}$ and GFP (LV-E/Syn-miR-34c) or GFP alone (LV-E/SynEGFP). To confirm the overexpression of miR-34c in vivo, these viruses were stereotactically injected intracranially and bilaterally into the CeA of wild-type mice. RNA was produced from individual amygdala punches dissected 1 week after lentiviral injection (Fig. 5E). RT-qPCR on individual punches confirmed an approximately fourfold overexpression of miR-34c in the amygdalae of mice injected with LV-E/Syn-miR-34c relative to mice injected with LV-E/Syn-EGFP control (Fig. 5F). Next, we explored the behavioral consequences of miR-34c overexpression in the CeA. LV-E/Syn-miR-34c was injected intracranially and bilaterally into the CeA of adult male C57BL/6 mice. Littermates injected with LV-E/Syn-EGFP served as controls. After 2 weeks of recovery, mice were tested for anxiety-like behavior using the DLT, EPM, and OF tests. To study recovery after a stressful event, the DLT and OF tests were repeated $24 \mathrm{~h}$ after $30 \mathrm{~min}$ of acute restraint stress. We subsequently determined locomotor 


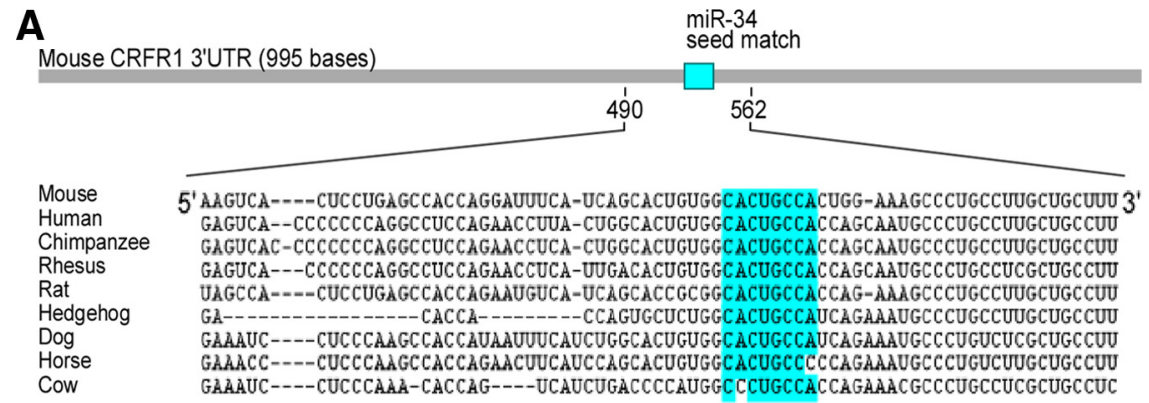

B
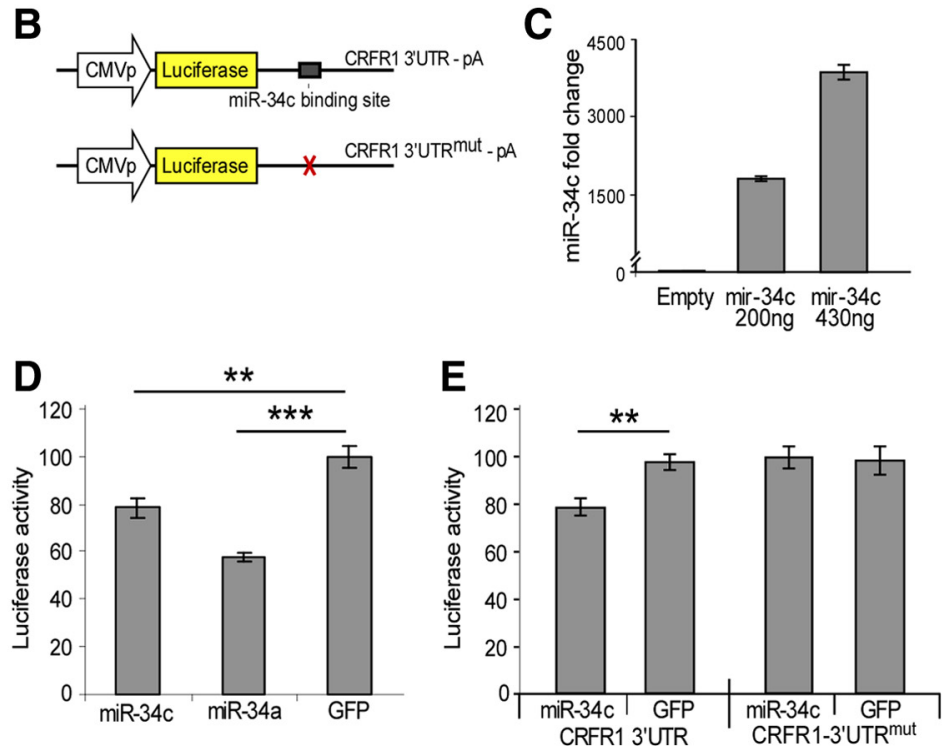

Figure 7. miR-34c regulates the expression of corticotropin releasing factor receptor type 1 via one seed match on its $3^{\prime}$ UTR. $\boldsymbol{A}_{\boldsymbol{\prime}}$ CRFR13' UTR is 995 bases long and carries one conserved miR seed match. Interspecies alignment of a 70 base sequence including the miR-34 seed match demonstrates its conservation among mammals (adapted from www.targetscan.org). $\boldsymbol{B}$, Illustration of intact (top) and mutant (bottom) PsiCHECK-2-CRFR1-3' UTR luciferase constructs. C, In vitro validation of miR-34c overexpression after transfection of HEK293T cells with pEGFP-miR-34c. D, E, Luciferase activity measured in HEK293T cells cotransfected with miR-34c-EGFP overexpressing, miR-34a-EGFP overexpressing, or GFP-expressing plasmid and a luciferase reporter plasmid carrying either an intact $(\boldsymbol{D})$ or mutant $(\boldsymbol{D}, \boldsymbol{E})$ form of CRFR1-3' UTR. Renilla luciferase activity was normalized by firefly luciferase expression levels and presented as percentage of activity achieved by the mutant form of CRFR1-3' UTR at the presence of miR-34c overexpression. CRFR1-3' UTR ${ }^{\text {mut }}$, Mutated from of CRFR1 3' UTR lacking the seed match for miR-34; UTR, untranslated region; CMVp, cytomegalovirus promoter; pA, SV40 polyadenylation signal. ${ }^{* *} p<0.01$.

behavior in the home cage across the circadian cycle. Only mice of which the histological examination confirmed infection predominantly in the CeA (Fig. $5 G$ ) were included in the analysis. Mice injected with LV-E/Syn-miR-34c into the CeA (CeA-miR$34 \mathrm{c}-\mathrm{OE}$ ) showed reduced anxiety-like behavior compared with control mice that were injected with GFP-expressing lentiviruses (CeA-EGFP; Fig. 6). In the DLT test, repeated-measures two-way ANOVA followed by post hoc Student's $t$ test comparisons revealed the following: $24 \mathrm{~h}$ after acute restraint stress, the CeAEGFP controls show indices of increased anxiety compared with their behavior under unstressed conditions, whereas the behavior of CeA-miR-34c-OE mice was unaffected by the acute stress. At $24 \mathrm{~h}$ after acute restraint stress, CeA-miR-34c-OE mice visited the illuminated chamber more (Fig. 6B), traveled a longer distance in the illuminated chamber (Fig. 6C), and had a shorter latency to enter the illuminated chamber (Fig. 6D) compared with CeA-EGFP controls. In a more stressful paradigm, the elevated plus maze (mice underwent the EPM procedure only once without an additional acute stress), CeA-miR-34c-OE mice traveled a significantly larger percentage of their overall distance in the open arms and spent more time in the open arms compared with
CeA-EGFP controls (Fig. 6E), further supporting an anxiolytic effect for miR-34c-OE under challenge. These effects cannot be attributed to a general elevation in locomotion because CeA-miR-34c-OE mice present normal home-cage locomotion compared with CeA-EGFP controls (Fig. $6 F)$. No significant differences were observed between the groups in the OF test under basal or stress conditions (data not shown). Collectively, these results suggest that miR-34c overexpression in the CeA has anxiolytic properties, which are more pronounced after a stressful event.

miR-34c targets corticotropin releasing factor receptor type 1 via a single-seed complementary site on the $3^{\prime}$ UTR of the receptor transcript

Intriguingly, one of the stress-related putative targets of miR-34 is the CRFR1 transcript, which is highly expressed in the amygdala and was demonstrated to increase anxiety-like behavior after pharmacological administration of the stress neuropeptide CRF (Heinrichs and Koob, 2004).

The mouse CRFR1-3' UTR is 995 bases long. When the vertebrate orthologs of CRFR1 transcript are compared (http:// targetscan.org), only one broadly conserved miRNA binding site is found on CRFR1-3' UTR. This site complements to the seed sequence of miR-34 family of miRNAs (Fig. $7 A)$. We further characterized this putative interaction between miR-34c and the $3^{\prime}$ UTR of CRFR1. Toward this end, an intact or mutated form of CRFR1-3' UTR (in which the seed match of miR-34c is absent) were cloned downstream of the luciferase gene in the PsiCHECK-2 expression plasmid (Promega; Fig. 7B). miR-34c overexpression plasmid was constructed by cloning the mouse pre-miR-34c genomic sequence between the CMV promoter and the EGFP sequence in the pEGFP-N1 plasmid (Clontech). We have verified the ability of this plasmid to induce miR34c overexpression in HEK293T cells by RT-qPCR (Fig. 7C). HEK293T cells were cotransfected with the PsiCHECK-2CRFR1-3' UTR vector and either the miR-34c overexpressing plasmid or a control pEGFP plasmid. miR-34c overexpression caused a $20 \%$ decrease in luciferase activity compared with a control pEGFP cotransfection (Fig. $7 D, E$ ). We also examined the ability of another miR-34 family member, miR-34a, to regulate the expression of CRFR 1 and found that miR-34a also cause an inhibition of up to $40 \%$ in luciferase expression (Fig. $7 D$ ). The effect of miR-34c is caused directly via recognition of the seed match on CRFR1-3' UTR because a mutated form of CRFR1-3' UTR, lacking the seed match for miR-34, failed to induce this inhibition (Fig. 7E).

To investigate whether miR-34 indeed functionally regulates CRF responsiveness, we studied the activation of cAMP signaling downstream to CRFR1 ligand-mediated activation. The mouse neuroblastoma N2a cells were confirmed to endogenously ex- 
A
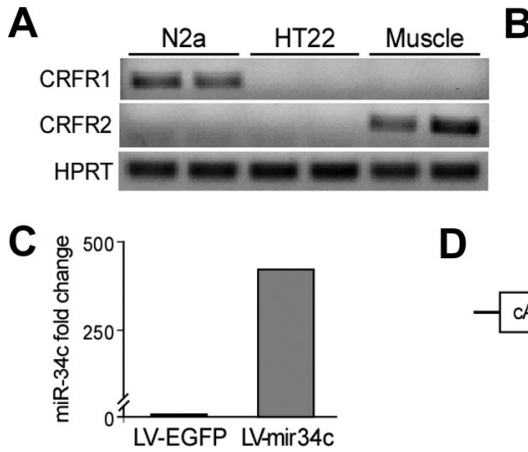

E

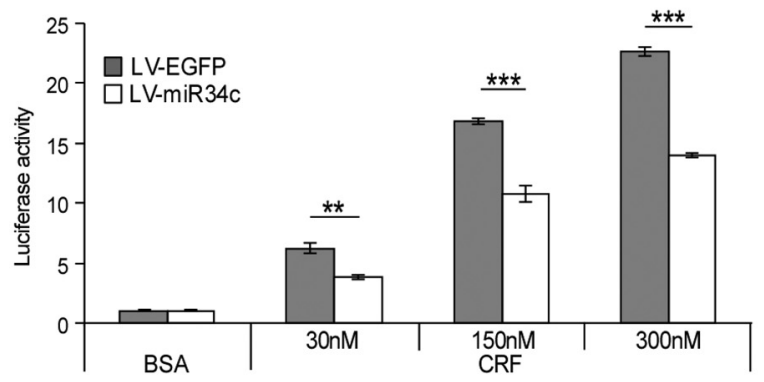

$\mathbf{F}$

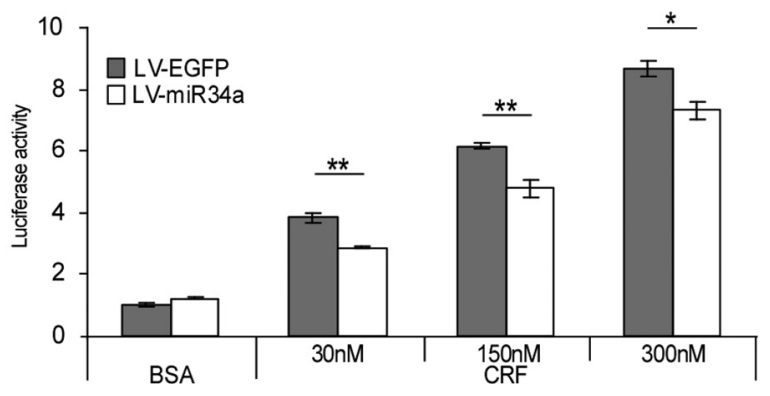

Figure 8. miR-34 functionally regulates CRF responsiveness of N2a cells that endogenously express CRFR1. A, RT-PCR for CRFR1, CRFR2, and HPRT on RNA produced from N2a murine neuroblastoma cell line (N2a), HT22 murine hippocampal cell line (HT22), and mouse muscle biopsies (Muscle). B, RT-qPCR for CRFR1 in N2a cells or amygdala punches, normalized by HPRT levels. Expression is presented as fold change relative to CRFR1 levels in the amygdala. Levels of CRFR1 mRNA in HT22 used as negative control are undetectable after 40 PCR cycles. N.D, Nondetected. $\boldsymbol{C}$, In vitro example of miR-34c overexpression in N2a cells after stable infection with LV-E/Syn-miR-34c, measured by qRT-PCR. D, Illustration of the CAMP-RE-firefly luciferase construct. $E, F$, Luciferase activity measured in N2a cells stably infected with either LV-E/Syn$\operatorname{EGFP}(\boldsymbol{E}, \boldsymbol{F}$, gray bars), LV-E/Syn-miR-34c ( $\boldsymbol{E}$, white bars), or LV-E/Syn-miR-34a ( $\boldsymbol{F}$, white bars) and transfected with a firefly luciferase reporter plasmid driven by a cAMP-RE. A Renilla luciferase vector served as normalizer. Firefly luciferase activity was normalized by Renilla luciferase expression levels and presented as fold change relative to basal luciferase activity (BSA treatment). CAMP-RE, A fragment of the EVX1 gene, which contains a potent cAMP response element. ${ }^{* *} p<0.01,{ }^{* * *} p<0.005$.

press CRFR1 but not CRFR2 (Fig. 8A,B) and were lentivirally infected to stably express EGFP, pre-miR-34c/EGFP, or pre-miR34a/EGFP under the control of the enhanced synapsin promoter. We have verified the overexpression of miR-34c in N2a cells by RT-qPCR (Fig. 8C). Stably infected cells were further transfected with a luciferase reporter vector whereby a fragment of the EVX1 gene, which contains a potent cAMP response element (cAMP$\mathrm{RE}$ ), drives the expression of the luciferase gene (Conkright et al., 2003) (Fig. 8D). This reporter is responsive to cAMP increase in cells after activation of certain types of $\mathrm{G}_{\mathrm{S}}$-protein-coupled receptors such as CRFR1 (Vita et al., 1993). At $24 \mathrm{~h}$ after transfection, cells were treated with either vehicle or CRF $(30,150$, and $300 \mathrm{nM}$ ) for $5 \mathrm{~h}$, and luciferase levels, reflecting activation of CRFR1 signaling, were measured. N2a cells show basal luciferase activity, which is identical for miR-34c overexpressing and GFP- expressing cells. However, N2a cells show a dose-dependent CRF-induced elevation in luciferase activity, which was reduced $\sim 40 \%$ in miR-34c overexpressing cells (Fig. 8 E) and up to $\sim 25 \%$ in miR-34a overexpressing cells (Fig. $8 F$ ) compared with GFPexpressing cells, across all CRF concentrations used.

\section{Discussion}

Here we show that Dicer ablation in the CeA of adult mice induced an increase in anxiety-like behavior. We further found several miRNA upregulated after exposure to acute stress. One of these miRNA, miR-34c had anxiolytic properties when lentivirally overexpressed in the CeA. Furthermore, miR-34a and miR$34 \mathrm{c}$ reduced the CRF responsiveness of CRFR1-expressing cells, and miR-34c was found to regulate CRFR1 transcript via a single evolutionary conserved seed match on its 3' UTR.

miRNA have been studied extensively in recent years and are suggested to play a major role in cell fate determination. The involvement of miRNAs in adult, non-malignant neural processes, such as the fine regulation of gene expression, essential for the adjustment of the cell and organism to the dynamic cellular and physiological conditions, is far less understood (Aumiller and Forstemann, 2008; Schratt, 2009). Here, we show that CeA adult neurons, depleted of Dicer in vivo, survive for up to 8 weeks after infection. This finding is in line with a recent study reporting a conditional Dicer $\mathrm{KO}$ in the forebrain of mature mice, in which signs of cell death were detected only 20 weeks after Cre induction (Konopka et al., 2010). In addition, previous work suggests that Dicer loss of function does not drive all neurons into apoptosis (Cuellar et al., 2008). Reports regarding the effect of Dicer ablation in the forebrain at different developmental and postnatal time points, using different CaMKIIa-Cre lines, demonstrate phenotypes with differing degrees of severity. When Dicer is ablated at a later time point [E15.5 (Davis et al., 2008), P18 (Hébert et al., 2010), 8-10 weeks (Konopka et al., 2010)], the phenotype that arises becomes more moderate and degeneration is delayed. Therefore, whereas miRNA biogenesis seems to be critical for the survival of developing or young neurons, the time course from Dicer ablation to degeneration may be different for fully functional mature neurons, perhaps because of differences in response of mature neurons to cell cycle initiation (Herrup and Yang, 2007) or via the long half-life of some essential miRNAs (van Rooij et al., 2007). Nonetheless, in the current study, we cannot rule out all possible neurodegenerative changes caused by Dicer ablation in the amygdala at the time point of behavioral and histological examinations and the contribution of such changes to the observed behavioral phenotype. Also, because we did not follow the behavioral or histological consequences of CeA Dicer ablation beyond the time point of 8 weeks after Cre induction, we cannot estimate at what time point degeneration may become prominent.

CeA-DCR-KO mice demonstrated heightened anxiety-like behavior but general locomotion was not affected. Of interest, corticosterone levels were not affected by the procedure, suggesting that the behavioral effects of CeA miRNA disruption are mediated by central and/or autonomic mechanisms rather than via the HPA axis. These data are in line with previous reports regarding BLA rather than CeA effect on HPA axis (Prewitt and Herman, 1997; Ulrich-Lai and Herman, 2009). Interestingly, recent studies have suggested miRNA regulation of glucocorticoid receptor protein levels in vitro (Uchida et al., 2008; de Kloet et al., 2009). Our results could be explained in part by glucocorticoid receptor upregulation in the amygdala, an interesting possibility that can be further examined in future studies. Collectively, miR- 
NAs are believed to regulate up to one-third of the genome (Lewis et al., 2005). Dicer depletion, affecting a full repertoire of miRNAs, is an extensive and severe manipulation, and the behavioral and genetic alterations caused by this manipulation probably represent the summation of many primary and secondary molecular effects rather than any specific alteration of a single biological process. Thus, identifying specific miRNAs that respond to stressful manipulation and determining their target genes may allow us to dissect the role of these miRNAs in regulating the central stress response. To that end, we have shown that acute stress alters miRNA expression pattern in the amygdala, with up to threefold increase or decrease in the expression of several miRNAs 90 min after stress initiation. One should bear in mind that the amygdala is not a homogeneous tissue, so that only a subset of cells is expected to be stress responsive. Therefore, we assume that any differential expression values obtained in these experiments underestimate the true changes within stress-responsive cells. We further used bioinformatic tools for the analysis of six upregulated miRNAs and have shown that these miRNAs potentially regulate the expression levels of a group of stress-related proteins. One of these predicted interactions is between miR-34c and the stress-linked CRFR1 transcript. We verified the upregulation of miR-34c after stress and demonstrated that lentiviral-induced miR-34c overexpression in the central amygdala has anxiolytic properties, which are more pronounced after a stressful challenge. Although informative, overexpression of any gene product or pharmacological substance may have a secondary rather than a physiologically relevant effect. Future research studying specific knockdown of miR-34c in the CeA using antisense oligonucleotides or lentiviral vectors may further elucidate the physiological role of miR-34c in stress-induced anxiety.

Data from in vivo pharmacological experiments demonstrated anxiogenic-like behavioral effects of CRF administration and anxiolytic-like activity of CRFR1-selective antagonists, establishing a role for CRF/CRFR1 system in the pathophysiology of anxiety-related disorders (Arborelius et al., 1999; Holsboer, 1999; Holmes et al., 2003; Heinrichs and Koob, 2004; Zorrilla et al., 2004; Bale, 2005; de Kloet et al., 2005; McEwen, 2005). In addition, limbic-specific conditional CRFR1 knock-out mice display decreased anxiety-like behavior, which is independent of the HPA axis activity (Müller et al., 2003).

We have shown that miR-34c and miR-34a modulates cell responsiveness to CRF and that it may do so via interaction with a single evolutionary conserved seed match on CRFR1 3' UTR. Interestingly, previous work had shown that CRFR1-3'UTR polymorphism may be correlated with panic disorder in humans (Keck et al., 2008). Intriguingly, basal hippocampal miR-34c levels in different mouse strains were found to correlate with measures of anxiety-like behavior, which were characterized previously for these mouse strains (Parsons et al., 2008). miR-34a was also found to be downregulated in the hippocampus of rats after treatment with mood stabilizers (Zhou et al., 2009). Collectively, these data support a role for the miR-34 family of miRNA in regulating genes that mediate the behavioral changes associated with the central stress response, within several brain regions. miR-34 family predicted targets also include other stress-related proteins [including metabotropic glutamate receptor 7 (Zhou et al., 2009), 5-hydroxytryptamine (serotonin) receptor 2C, GABA receptor $\alpha 4$, and brain-derived neurotrophic factor], suggesting that the miR-34 family of miRNA may play a role in regulating several amygdalar genes that collectively modulate the behavioral response to stress.
The miR-34 family of miRNA has been previously associated with cancer, in which they appear to act as tumor suppressor genes via their interaction with P53 (Corney et al., 2007; He et al., 2007a,b; Raver-Shapira et al., 2007; Yamakuchi et al., 2008; Yamakuchi and Lowenstein, 2009). It is reasonable nonetheless to speculate that miRNA harboring cell-cycle-related functions in dividing and differentiating cells may have evolutionally acquired additional roles in terminally differentiated postmitotic cells such as neurons (for a similar view, see Frank and Tsai, 2009).

We propose that miRNAs may contribute to restoration of homeostasis in stress-responsive circuits by their involvement in regulating the expression of proteins that are elevated after challenging experiences. Without the ability to control the levels of these "homeostasis guards," the stress response may extend beyond beneficial levels, whereas elevated levels of these mediators may prove protective. Future studies will be required to establish this hypothesis and determine the identity of other stressmodulating miRNAs and their targets, in various cell populations in the adult brain. Such findings may lead to the development of novel treatments for anxiety disorders and depression and other stress-related psychiatric and physiological conditions.

\section{References}

Arborelius L, Owens MJ, Plotsky PM, Nemeroff CB (1999) The role of corticotropin-releasing factor in depression and anxiety disorders. J Endocrinol 160:1-12.

Ashraf SI, Kunes S (2006) A trace of silence: memory and microRNA at the synapse. Curr Opin Neurobiol 16:535-539.

Aumiller V, Förstemann K (2008) Roles of microRNAs beyond development-metabolism and neural plasticity. Biochim Biophys Acta 1779:692-696.

Babiarz JE, Ruby JG, Wang Y, Bartel DP, Blelloch R (2008) Mouse ES cells express endogenous shRNAs, siRNAs, and other Microprocessorindependent, Dicer-dependent small RNAs. Genes Dev 22:2773-2785.

Bale TL (2005) Sensitivity to stress: dysregulation of CRF pathways and disease development. Horm Behav 48:1-10.

Bartel DP (2009) MicroRNAs: target recognition and regulatory functions. Cell 136:215-233.

Baudry A, Mouillet-Richard S, Schneider B, Launay JM, Kellermann O (2010) miR-16 targets the serotonin transporter: a new facet for adaptive responses to antidepressants. Science 329:1537-1541.

Beveridge NJ, Gardiner E, Carroll AP, Tooney PA, Cairns MJ (2010) Schizophrenia is associated with an increase in cortical microRNA biogenesis. Mol Psychiatry 15:1176-1189.

Bosch OJ, Meddle SL, Beiderbeck DI, Douglas AJ, Neumann ID (2005) Brain oxytocin correlates with maternal aggression: link to anxiety. J Neurosci 25:6807-6815.

Carbon S, Ireland A, Mungall CJ, Shu S, Marshall B, Lewis S (2009) AmiGO: online access to ontology and annotation data. Bioinformatics 25:288-289.

Carthew RW, Sontheimer EJ (2009) Origins and mechanisms of miRNAs and siRNAs. Cell 136:642-655.

Chekulaeva M, Filipowicz W (2009) Mechanisms of miRNA-mediated post-transcriptional regulation in animal cells. Curr Opin Cell Biol 21:452-460.

Cheloufi S, Dos Santos CO, Chong MM, Hannon GJ (2010) A dicerindependent miRNA biogenesis pathway that requires Ago catalysis. Nature 465:584-589.

Chen A, Perrin M, Brar B, Li C, Jamieson P, Digruccio M, Lewis K, Vale W (2005) Mouse corticotropin-releasing factor receptor type 2alpha gene: isolation, distribution, pharmacological characterization and regulation by stress and glucocorticoids. Mol Endocrinol 19:441-458.

Cheng HY, Papp JW, Varlamova O, Dziema H, Russell B, Curfman JP, Nakazawa T, Shimizu K, Okamura H, Impey S, Obrietan K (2007) microRNA modulation of circadian-clock period and entrainment. Neuron 54:813-829.

Conkright MD, Guzmán E, Flechner L, Su AI, Hogenesch JB, Montminy M (2003) Genome-wide analysis of CREB target genes reveals a core promoter requirement for cAMP responsiveness. Mol Cell 11:1101-1108. 
Corney DC, Flesken-Nikitin A, Godwin AK, Wang W, Nikitin AY (2007) MicroRNA-34b and MicroRNA-34c are targets of p53 and cooperate in control of cell proliferation and adhesion-independent growth. Cancer Res 67:8433-8438.

Cuellar TL, Davis TH, Nelson PT, Loeb GB, Harfe BD, Ullian E, McManus MT (2008) Dicer loss in striatal neurons produces behavioral and neuroanatomical phenotypes in the absence of neurodegeneration. Proc Natl Acad Sci U S A 105:5614-5619.

Davis CJ, Bohnet SG, Meyerson JM, Krueger JM (2007) Sleep loss changes microRNA levels in the brain: a possible mechanism for state-dependent translational regulation. Neurosci Lett 422:68-73.

Davis TH, Cuellar TL, Koch SM, Barker AJ, Harfe BD, McManus MT, Ullian EM (2008) Conditional loss of Dicer disrupts cellular and tissue morphogenesis in the cortex and hippocampus. J Neurosci 28:4322-4330.

de Kloet ER, Joëls M, Holsboer F (2005) Stress and the brain: from adaptation to disease. Nat Rev Neurosci 6:463-475.

de Kloet ER, Fitzsimons CP, Datson NA, Meijer OC, Vreugdenhil E (2009) Glucocorticoid signaling and stress-related limbic susceptibility pathway: about receptors, transcription machinery and microRNA. Brain Res 1293:129-141.

De Pietri Tonelli D, Pulvers JN, Haffner C, Murchison EP, Hannon GJ, Huttner WB (2008) miRNAs are essential for survival and differentiation of newborn neurons but not for expansion of neural progenitors during early neurogenesis in the mouse embryonic neocortex. Development 135:3911-3921.

Dugas JC, Cuellar TL, Scholze A, Ason B, Ibrahim A, Emery B, Zamanian JL, Foo LC, McManus MT, Barres BA (2010) Dicer1 and miR-219 Are required for normal oligodendrocyte differentiation and myelination. Neuron 65:597-611.

Ebner K, Bosch OJ, Krömer SA, Singewald N, Neumann ID (2005) Release of oxytocin in the rat central amygdala modulates stress-coping behavior and the release of excitatory amino acids. Neuropsychopharmacology 30:223-230.

Edbauer D, Neilson JR, Foster KA, Wang CF, Seeburg DP, Batterton MN, Tada T, Dolan BM, Sharp PA, Sheng M (2010) Regulation of synaptic structure and function by FMRP-associated microRNAs miR-125b and miR-132. Neuron 65:373-384.

Elliott E, Ezra-Nevo G, Regev L, Neufeld-Cohen A, Chen A (2010) Resilience to social stress coincides with functional DNA methylation of the Crf gene in adult mice. Nat Neurosci 13:1351-1353.

Fabian MR, Sonenberg N, Filipowicz W (2010) Regulation of mRNA translation and stability by microRNAs. Annu Rev Biochem 79:351-379.

Fénelon K, Mukai J, Xu B, Hsu PK, Drew LJ, Karayiorgou M, Fischbach GD, Macdermott AB, Gogos JA (2011) Deficiency of Dgcr8, a gene disrupted by the 22q11.2 microdeletion, results in altered short-term plasticity in the prefrontal cortex. Proc Natl Acad Sci U S A 108:4447-4452.

Frank CL, Tsai LH (2009) Alternative functions of core cell cycle regulators in neuronal migration, neuronal maturation, and synaptic plasticity. Neuron 62:312-326.

Haramati S, Chapnik E, Sztainberg Y, Eilam R, Zwang R, Gershoni N, McGlinn E, Heiser PW, Wills AM, Wirguin I, Rubin LL, Misawa H, Tabin CJ, Brown RH Jr, Chen A, Hornstein E (2010) miRNA malfunction causes spinal motor neuron disease. Proc Natl Acad Sci U S A 107:13111-13116.

Harfe BD, McManus MT, Mansfield JH, Hornstein E, Tabin CJ (2005) The RNaseIII enzyme Dicer is required for morphogenesis but not patterning of the vertebrate limb. Proc Natl Acad Sci U S A 102:10898-10903.

He L, He X, Lim LP, de Stanchina E, Xuan Z, Liang Y, Xue W, Zender L, Magnus J, Ridzon D, Jackson AL, Linsley PS, Chen C, Lowe SW, Cleary MA, Hannon GJ (2007a) A microRNA component of the p53 tumour suppressor network. Nature 447:1130-1134.

He X, He L, Hannon GJ (2007b) The guardian's little helper: microRNAs in the p53 tumor suppressor network. Cancer Res 67:11099-11101.

Hébert SS, Papadopoulou AS, Smith P, Galas MC, Planel E, Silahtaroglu AN, Sergeant N, Buée L, De Strooper B (2010) Genetic ablation of Dicer in adult forebrain neurons results in abnormal tau hyperphosphorylation and neurodegeneration. Hum Mol Genet 19:3959-3969.

Heinrichs SC, Koob GF (2004) Corticotropin-releasing factor in brain: a role in activation, arousal, and affect regulation. J Pharmacol Exp Ther 311:427-440

Herrup K, Yang Y (2007) Cell cycle regulation in the postmitotic neuron: oxymoron or new biology? Nat Rev Neurosci 8:368-378.

Hioki H, Kameda H, Nakamura H, Okunomiya T, Ohira K, Nakamura K,
Kuroda M, Furuta T, Kaneko T (2007) Efficient gene transduction of neurons by lentivirus with enhanced neuron-specific promoters. Gene Ther 14:872-882.

Holmes A, Heilig M, Rupniak NM, Steckler T, Griebel G (2003) Neuropeptide systems as novel therapeutic targets for depression and anxiety disorders. Trends Pharmacol Sci 24:580-588.

Holsboer F (1999) The rationale for corticotropin-releasing hormone receptor (CRH-R) antagonists to treat depression and anxiety. J Psychiatr Res 33:181-214.

Im HI, Hollander JA, Bali P, Kenny PJ (2010) MeCP2 controls BDNF expression and cocaine intake through homeostatic interactions with microRNA-212. Nat Neurosci 13:1120-1127.

Jankord R, Herman JP (2008) Limbic regulation of hypothalamo-pituitaryadrenocortical function during acute and chronic stress. Ann N Y Acad Sci 1148:64-73.

Joëls M, Baram TZ (2009) The neuro-symphony of stress. Nat Rev Neurosci 10:459-466.

Keck ME, Kern N, Erhardt A, Unschuld PG, Ising M, Salyakina D, Müller MB, Knorr CC, Lieb R, Hohoff C, Krakowitzky P, Maier W, Bandelow B, Fritze J, Deckert J, Holsboer F, Müller-Myhsok B, Binder EB (2008) Combined effects of exonic polymorphisms in CRHR1 and AVPR1B genes in a case/control study for panic disorder. Am J Med Genet B Neuropsychiatr Genet 147B:1196-1204.

Keen-Rhinehart E, Michopoulos V, Toufexis DJ, Martin EI, Nair H, Ressler KJ, Davis M, Owens MJ, Nemeroff CB, Wilson ME (2009) Continuous expression of corticotropin-releasing factor in the central nucleus of the amygdala emulates the dysregulation of the stress and reproductive axes. Mol Psychiatry 14:37-50.

Kim AH, Reimers M, Maher B, Williamson V, McMichael O, McClay JL, van den Oord EJ, Riley BP, Kendler KS, Vladimirov VI (2010) MicroRNA expression profiling in the prefrontal cortex of individuals affected with schizophrenia and bipolar disorders. Schizophr Res 124:183-191.

Kim J, Inoue K, Ishii J, Vanti WB, Voronov SV, Murchison E, Hannon G, Abeliovich A (2007) A MicroRNA feedback circuit in midbrain dopamine neurons. Science 317:1220-1224.

Kim VN, Han J, Siomi MC (2009) Biogenesis of small RNAs in animals. Nat Rev Mol Cell Biol 10:126-139.

Konopka W, Kiryk A, Novak M, Herwerth M, Parkitna JR, Wawrzyniak M, Kowarsch A, Michaluk P, Dzwonek J, Arnsperger T, Wilczynski G, Merkenschlager M, Theis FJ, Köhr G, Kaczmarek L, Schütz G (2010) MicroRNA loss enhances learning and memory in mice. J Neurosci 30:14835-14842.

Koob GF, Heinrichs SC (1999) A role for corticotropin releasing factor and urocortin in behavioral responses to stressors. Brain Res 848:141-152.

Krishnan V, Han MH, Graham DL, Berton O, Renthal W, Russo SJ, Laplant Q, Graham A, Lutter M, Lagace DC, Ghose S, Reister R, Tannous P, Green TA, Neve RL, Chakravarty S, Kumar A, Eisch AJ, Self DW, Lee FS, Tamminga CA, Cooper DC, Gershenfeld HK, Nestler EJ (2007) Molecular adaptations underlying susceptibility and resistance to social defeat in brain reward regions. Cell 131:391-404.

Krol J, Loedige I, Filipowicz W (2010a) The widespread regulation of microRNA biogenesis, function and decay. Nat Rev Genet 11:597-610.

Krol J, Busskamp V, Markiewicz I, Stadler MB, Ribi S, Richter J, Duebel J, Bicker S, Fehling HJ, Schübeler D, Oertner TG, Schratt G, Bibel M, Roska B, Filipowicz W (2010b) Characterizing light-regulated retinal microRNAs reveals rapid turnover as a common property of neuronal microRNAs. Cell 141:618-631.

Kuperman Y, Issler O, Regev L, Musseri I, Navon I, Neufeld-Cohen A, Gil S, Chen A (2010) Perifornical Urocortin-3 mediates the link between stress-induced anxiety and energy homeostasis. Proc Natl Acad Sci U S A 107:8393-8398

Kuperman Y, Issler O, Vaughan J, Bilezikjian L, Vale W, Chen A (2011) Expression and regulation of corticotropin-releasing factor receptor type $2 \beta$ in developing and mature mouse skeletal muscle. Mol Endocrinol $25: 157-169$

Leung AK, Sharp PA (2010) MicroRNA functions in stress responses. Mol Cell 40:205-215.

Lewis BP, Burge CB, Bartel DP (2005) Conserved seed pairing, often flanked by adenosines, indicates that thousands of human genes are microRNA targets. Cell 120:15-20.

Li X, Jin P (2010) Roles of small regulatory RNAs in determining neuronal identity. Nat Rev Neurosci 11:329-338. 
McEwen BS (2005) Glucocorticoids, depression, and mood disorders: structural remodeling in the brain. Metabolism 54:20-23.

McEwen BS (2007) Physiology and neurobiology of stress and adaptation: central role of the brain. Physiol Rev 87:873-904.

Müller MB, Zimmermann S, Sillaber I, Hagemeyer TP, Deussing JM, Timpl P, Kormann MS, Droste SK, Kühn R, Reul JM, Holsboer F, Wurst W (2003) Limbic corticotropin-releasing hormone receptor 1 mediates anxiety-related behavior and hormonal adaptation to stress. Nat Neurosci 6:1100-1107.

Neufeld-Cohen A, Evans AK, Getselter D, Spyroglou A, Hill A, Gil S, Tsoory M, Beuschlein F, Lowry CA, Vale W, Chen A (2010a) Urocortin-1 and -2 double-deficient mice show robust anxiolytic phenotype and modified serotonergic activity in anxiety circuits. Mol Psychiatry [Erratum (2010) 15:442] 15:426-441.

Neufeld-Cohen A, Tsoory MM, Evans AK, Getselter D, Gil S, Lowry CA, Vale WW, Chen A (2010b) A triple urocortin knockout mouse model reveals an essential role for urocortins in stress recovery. Proc Natl Acad Sci U S A 107:19020-19025.

Parsons MJ, Grimm CH, Paya-Cano JL, Sugden K, Nietfeld W, Lehrach H, Schalkwyk LC (2008) Using hippocampal microRNA expression differences between mouse inbred strains to characterise miRNA function. Mamm Genome 19:552-560.

Paxinos F, Franklin KB (2001) The mouse brain in stereotaxic coordinates. San Diego: Academic.

Pfeifer A, Brandon EP, Kootstra N, Gage FH, Verma IM (2001) Delivery of the Cre recombinase by a self-deleting lentiviral vector: efficient gene targeting in vivo. Proc Natl Acad Sci U S A 98:11450-11455.

Prewitt CM, Herman JP (1997) Hypothalamo-pituitary-adrenocortical regulation following lesions of the central nucleus of the amygdala. Stress 1:263-280.

Raver-Shapira N, Marciano E, Meiri E, Spector Y, Rosenfeld N, Moskovits N, Bentwich Z, Oren M (2007) Transcriptional activation of miR-34a contributes to p53-mediated apoptosis. Mol Cell 26:731-743.

Rogan MT, LeDoux JE (1996) Emotion: systems, cells, synaptic plasticity. Cell 85:469-475.

Roozendaal B, McEwen BS, Chattarji S (2009) Stress, memory and the amygdala. Nat Rev Neurosci 10:423-433.

Schaefer A, O'Carroll D, Tan CL, Hillman D, Sugimori M, Llinas R, Greengard P (2007) Cerebellar neurodegeneration in the absence of microRNAs. J Exp Med 204:1553-1558.

Schaefer A, Im HI, Venø MT, Fowler CD, Min A, Intrator A, Kjems J, Kenny PJ, O'Carroll D, Greengard P (2010) Argonaute 2 in dopamine 2 receptor-expressing neurons regulates cocaine addiction. J Exp Med 207:1843-1851.

Schratt G (2009) Fine-tuning neural gene expression with microRNAs. Curr Opin Neurobiol 19:213-219.
Srinivas S, Watanabe T, Lin CS, William CM, Tanabe Y, Jessell TM, Costantini F (2001) Cre reporter strains produced by targeted insertion of EYFP and ECFP into the ROSA26 locus. BMC Dev Biol 1:4.

Sztainberg Y, Kuperman Y, Tsoory M, Lebow M, Chen A (2010) The anxiolytic effect of environmental enrichment is mediated via amygdalar CRF receptor type 1. Mol Psychiatry 15:905-917.

Tabarés-Seisdedos R, Rubenstein JL (2009) Chromosome 8p as a potential hub for developmental neuropsychiatric disorders: implications for schizophrenia, autism and cancer. Mol Psychiatry 14:563-589.

Tiscornia G, Singer O, Verma IM (2006) Production and purification of lentiviral vectors. Nat Protoc 1:241-245.

Uchida S, Nishida A, Hara K, Kamemoto T, Suetsugi M, Fujimoto M, Watanuki T, Wakabayashi Y, Otsuki K, McEwen BS, Watanabe Y (2008) Characterization of the vulnerability to repeated stress in Fischer 344 rats: possible involvement of microRNA-mediated down-regulation of the glucocorticoid receptor. Eur J Neurosci 27:2250-2261.

Ulrich-Lai YM, Herman JP (2009) Neural regulation of endocrine and autonomic stress responses. Nat Rev Neurosci 10:397-409.

van Rooij E, Sutherland LB, Qi X, Richardson JA, Hill J, Olson EN (2007) Control of stress-dependent cardiac growth and gene expression by a microRNA. Science 316:575-579.

Vita N, Laurent P, Lefort S, Chalon P, Lelias JM, Kaghad M, Le Fur G, Caput D, Ferrara P (1993) Primary structure and functional expression of mouse pituitary and human brain corticotrophin releasing factor receptors. FEBS Lett 335:1-5.

Wibrand K, Panja D, Tiron A, Ofte ML, Skaftnesmo KO, Lee CS, Pena JT, Tuschl T, Bramham CR (2010) Differential regulation of mature and precursor microRNA expression by NMDA and metabotropic glutamate receptor activation during LTP in the adult dentate gyrus in vivo. Eur J Neurosci 31:636-645.

Yamakuchi M, Lowenstein CJ (2009) MiR-34, SIRT1 and p53: the feedback loop. Cell Cycle 8:712-715.

Yamakuchi M, Ferlito M, Lowenstein CJ (2008) miR-34a repression of SIRT1 regulates apoptosis. Proc Natl Acad Sci U S A 105:13421-13426.

Zhao X, He X, Han X, Yu Y, Ye F, Chen Y, Hoang T, Xu X, Mi QS, Xin M, Wang F, Appel B, Lu QR (2010) MicroRNA-mediated control of oligodendrocyte differentiation. Neuron 65:612-626.

Zhou R, Yuan P, Wang Y, Hunsberger JG, Elkahloun A, Wei Y, DamschroderWilliams P, Du J, Chen G, Manji HK (2009) Evidence for selective microRNAs and their effectors as common long-term targets for the actions of mood stabilizers. Neuropsychopharmacology 34:1395-1405.

Zorrilla EP, Reinhardt LE, Valdez GR, Inoue K, Rivier JE, Vale WW, Koob GF (2004) Human urocortin 2, a corticotropin-releasing factor (CRF)2 agonist, and ovine CRF, a CRF1 agonist, differentially alter feeding and motor activity. J Pharmacol Exp Ther 310:1027-1034. 